\title{
Turning the Clock Ahead: Potential Preclinical and Clinical Neuropharmacological Targets for Alcohol Dependence
}

\author{
Lorenzo Leggio $^{1,2, *}$, Silvia Cardone ${ }^{2}$, Anna Ferrulli ${ }^{2}$, George A. Kenna ${ }^{1}$, Marco Diana ${ }^{3}$, Robert M. Swift ${ }^{1,4}$, \\ and Giovanni Addolorato ${ }^{2}$
}

${ }^{1}$ Center for Alcohol and Addiction Studies, Brown University, and ${ }^{2}$ Institute of Internal Medicine, Catholic University of Rome, Rome, Italy; "G. Minardi" Laboratory of Cognitive Neurosciences, Department of Drug Sciences, University of Sassari, Sassari, Italy, ${ }^{4}$ VA Medical Center, Providence, RI, USA

\begin{abstract}
Treating alcohol use disorders represents a main goal in public health, but the effect of current medications is modest. Thus, in the last few years, research has been focusing on identifying new neuropharmacological targets for alcohol dependence. This review will summarize recent research, which has identified new targets to treat alcohol dependence. A variety of systems have been investigated, such as the endocannabinoid system, modulators of glutamatergic transmission, corticotropin-releasing factor (CRF), neuropeptide $\mathrm{Y}$ (NPY), nociceptin, glial cell line-derived neurotrophic factor (GDNF), acetaldehyde (ACD), substance P and Neurokinin 1 (NK1) receptor, nicotinic acetylcholine receptors (nAchRs), alpha-adrenergic receptor, and many others. Compared to preclinical studies, only a few clinical studies have been conducted so far. Thus, there is a critical need to translate successful preclinical results into human clinical trials. However, since some clinical studies have failed to replicate preclinical findings, future research will have not only to identify more efficacious medications, but also delineate the best match between a particular pharmacotherapy with a specific alcoholic subtype.
\end{abstract}

Keywords: Alcohol dependence, neurobiology, pharmacotherapy.

\section{INTRODUCTION}

Alcohol induces several neurobiological changes in the central nervous system (CNS). Molecular pharmacology studies demonstrate that alcohol has only a few known primary targets, which include N-methyl-D-aspartic acid (NMDA), $\gamma$-aminobutyric acid (GABA), glycine, serotonin, nicotinic acetylcholine (Ach) receptors, calcium $\left(\mathrm{Ca}^{+2}\right)$ and potassium $\left(\mathrm{K}^{+}\right)$channels [1]. The initial exposure of alcohol to specific targets in the brain leads to the typical acute subjective psychotropic effects of this drug, ranging from disinhibition to sedation and even hypnosis, in parallel with increased alcohol concentration. Alcohol also acts indirectly on a variety of neurotransmitter/neuropeptide systems including monoamines such as dopamine (DA), beta-endorphin, and endocannabinoids, and is crucial for the initiation of alcohol reinforcement and reward.

Traditionally, the activity of the mesolimbic DA system plays a crucial role during the initial phase of alcohol consumption responding with an increase in activity after acute alcohol challenge [2]. However, after chronic treatment the DA system appears to reduce its tonic activity [3-5] and these effects are accompanied by similar changes in the human brain [6,7]. Thus, it appears that a "normalization" of DA activity would be desirable, therapeutically speaking. Indeed, the "hypodopaminergic hypothesis" suggests that "boosting" the DA system should ameliorate compulsive drug/alcohol use. Chronic alcohol consumption affects virtually all brain neurotransmitters. These changes likely represent part of the pathophysiological process of alcohol dependence (AD) and contribute to the compulsive use and loss of control over drinking seen in alcoholism. Compulsive alcohol drinking is characterized by a decrease in the function of the reward neurocircuitry and a recruitment of antireward/stress mechanisms, with a hypertrophic corticotropin-releasing factor (CRF) system and a hyperfunctional glutamatergic system [8].

*Address correspondence to this author at the Center for Alcohol and Addiction Studies, Brown University Medical School, Box G S 121-4; Providence, RI, 02912, USA; Tel: (401) 863-6638; Fax: (401) 863-6647;

E-mail: Lorenzo_Leggio@brown.edu
These alcohol-induced neurobiological changes represent possible molecular targets for pharmacotherapies of alcoholism. Pharmacotherapies for alcoholism may either modulate or block the rewarding effects of alcohol or stabilize neurobiological systems dysregulated by chronic alcohol intake, which help to facilitate abstinence or greatly reduce alcohol consumption. Consistent with these concepts, evidence is available that pharmacological treatments can prolong the time to relapse following cessation of heavy drinking, or decrease the number of heavy drinking days [9].

In the United States (US), disulfiram, naltrexone (oral and injectable) and acamprosate are approved medications for the treatment of AD. Several other medications (e.g. topiramate, ondansetron, baclofen, and others) are also under investigation and hold significant promise. While other articles in this special issue review many of these medications [10-16] the aim of this review is to summarize recent research, which attempts to identify new future neuropharmacological targets. These novel targets may eventually lead to the development of new medications for $\mathrm{AD}$.

\section{CANNABINOID RECEPTORS}

The endocannabinoid system has an important role in the regulation of the pharmacological and behavioural effects of alcohol, preference, drinking, and vulnerability to relapse [17-19].

The main brain endocannabinoid receptor subtype, the cannabinoid-1 (CB1) receptor, is widely distributed in the CNS, with high density in the brain reward circuitry, including the ventral tegmental area (VTA) and the nucleus accumbens (NAc) [20]. Endocannabinoids that activate $\mathrm{CB} 1$ receptors present on axon terminals of GABAergic neurons in the VTA act as retrograde messengers, by inhibiting GABA synaptic transmission, and thus removing this inhibitory input on dopaminergic neurons. Glutamate transmission from neurons of the prefrontal cortex in the VTA and NAc is similarly modulated by the activation of CB1 receptors. Acute alcoholinduced DA release in the NAc is mediated by CB1 receptors and chronic ethanol vapor exposure increases brain endogenous endocannabinoids levels and down-regulate CB1 receptors [20-22]. Thus, the endocannabinoid system is involved in the rewarding effects of alcohol; as alcohol increases dopaminergic neuron firing rates, the release of endocannabinoids in the VTA further enhances dopaminergic activity [23]. 
Consistent with the evidence summarized above, enhancement of the $\mathrm{CB} 1$ receptor function increases ethanol drinking. For example, acute administration of the CB1 receptor agonists WIN 55,2122 and CP 55,940, significantly stimulates voluntary ethanol intake in ethanol-preferring sP rats [24]. In contrast, genetic or pharmacological blockade of the CB1 receptor decreases in ethanol consumption. Several studies with CB1 receptor knock-out mice show that genetic CB1 receptor blockade results in a reduction in voluntary ethanol intake [25-29]. Pharmacological blockade with rimonabant, a potent, selective, and orally active blocker of the central CB1 receptors [30] prevents habituation to ethanol drinking, when administered at the start of exposure to alcohol in genetically-selected alcohol-preferring rats [31-34]. Similarly, using different animal models of excessive alcohol drinking in which alcohol intake was already established, rimonabant (administered either acutely or repeatedly) reduced ethanol intake [35-38], and suppressed alcohol self-administration [39-41]. Notably, rimonabant augmented inhibitory postsynaptic potentials, revealing a tonic endocannabinoid activity that decreased inhibitory transmission in central amygdala [42]. Furthermore, experiments employing validated animal models for human relapse (e.g. 'alcohol deprivation effect', 'reinstatement model') have shown the efficacy of both rimonabant in suppressing relapse in alcohol-preferring animals [43-46], and surinabant, in preventing habituation to ethanol drinking and in showing antirelapse properties [47-48].

Two human studies testing rimonabant for alcoholism have been conducted. The first study was a Phase $2 \mathrm{a}$, double-blind, placebo-controlled study in which 258 recently detoxified AD patients received a 12 -week treatment with rimonabant $(20 \mathrm{mg} / \mathrm{d})$ or placebo [49]. This trial did not show any statistically significant difference between the two groups in time to first drink, time to first heavy drink, nor in the cumulative abstinence duration (days of abstinence). The second study was a Phase I/II, double-blind, placebocontrolled laboratory study aimed at assessing the effect of rimonabant $(20 \mathrm{mg} / \mathrm{d})$ on alcohol consumption in 49 non-treatment seeking heavy alcohol drinkers [50]. In the naturalistic (outpatient) phase of the study, rimonabant failed to alter daily alcohol consumption. In the experimental (inpatient) phase of the study, after ingestion of a priming dose of alcohol, participants had the choice to drink up to an additional eight alcohol drinks or receive a small amount of money for each non consumed drink. Again, rimonabant did not significantly alter the number of alcohol drinks consumed during the self-administration experiment.

In conclusion, while animal studies suggest that the $\mathrm{CB} 1$ receptor represents a new target for the treatment of $\mathrm{AD}$, human studies do not demonstrate any beneficial effect of rimonabant, compared to placebo, on drinking outcomes. Thus, future studies are needed to investigate the discrepancies between animal and human studies. We also note that there are concerns that the medication may increase depression and suicidality [51].

\section{MODULATORS OF GLUTAMATERGIC TRANSMISSION}

Glutamate is the primary excitatory neurotransmitter in the brain and a mediator of the synaptic plasticity required for organisms to adapt behaviour to a changing environment [52,53]. Glutamate, through sensitization and drug-seeking behaviours, plays a crucial role in the pathogenesis of alcohol and drug addiction. In particular, the cycle of alcohol intoxication, withdrawal, abstinence, and relapse induces a hyperglutamatergic state in brain regions associated with alcohol reward, which may contribute in increased alcohol intake and vulnerability to relapse in alcoholics [20].

Glutamate receptors fall into one of two categories: ligandgated ion channels (i.e., ionotropic glutamate receptors, or iGluRs) and G-protein coupled receptors (i.e., metabotropic glutamate receptors, or mGluRs) [54]. Both groups of glutamate receptors seem to play a role in the neurobiological mechanisms on the basis of alcohol dependence, thus being suggested as potential targets for alcohol pharmacotherapy.

Three different types of iGluRs have been identified: the NMDA receptor, the $\alpha$-amino-3-hydroxy-5-methylisoxazole-4propionic acid (AMPA) receptor, and the kainic acid (KA) receptor. These receptors are ligand-gated ion channels that mediate fast excitatory neurotransmission [54]. Numerous preclinical studies show that iGluR ligands alter the reinforcing effects of drugs of abuse, such as ethanol, and can modify drinking behaviour [55]. NMDA antagonists can attenuate the alcohol deprivation effect, cue-induced reinstatement of alcohol-seeking behaviour, acquisition of ethanol conditioned place preference and sensitization to the locomotor stimulant effects of low doses of ethanol [55]. However, Vosler and colleagues [56] showed that NMDA antagonists, such as MK-801, while producing ethanol-like discriminative stimulus effects, did not reinstate ethanol-seeking behaviour. AMPA/KA receptor antagonists also attenuate operant ethanol reinforcement and cue-induced reinstatement in preclinical studies [55]. However, in some of these studies, an effect in reducing sucrose or saccharin reinforcement by NMDA or AMPA/KA ligands has been observed, thus suggesting a non selective action in reducing alcohol intake.

When tested in humans, the majority of iGluR antagonists had significant side effects, including memory loss, disorientation, and psychotic symptoms. Memantine is one of the few NMDA receptor antagonists that is generally well tolerated by humans and does not appear to have abuse potential [57]. Memantine is a more specific non-competitive NMDA receptor antagonist that has been used in Europe for over 20 years to treat neurological diseases. Memantine was approved by the Food and Drug Administration (FDA) in 2003 for the treatment of Alzheimer's disease. Bisaga and Evans [58] evaluated the acute effects of memantine $(15$ and $30 \mathrm{mg})$ in moderate drinkers (20 drinks/week), who had no diagnosis of $\mathrm{AD}$ and were not looking for treatment. In this study, memantine $(30 \mathrm{mg})$ reduced alcohol craving before alcohol administration. Krupitsky and collegues [59] evaluated the effects of memantine $(20 \mathrm{mg} / \mathrm{d}$ and $40 \mathrm{mg} / \mathrm{d}$ ) on alcohol craving where alcohol craving was assessed before and after exposure to alcohol cues. Results of this study showed that memantine attenuated alcohol cue-induced craving in a dose-related fashion. Moreover, Krupitsky and collegues [60] also showed an effect of memantine $10 \mathrm{mg} / \mathrm{d}$ in reducing withdrawal symptoms in detoxified alcoholics However, a double-blind placebo-controlled pilot study with memantine for $\mathrm{AD}$ found no differences in drinks per day and drinks per drinking day between the two groups [61]. Indeed, there was a significantly greater percentage of abstinence days in the placebo compared to the memantine group.

The anticonvulsivant levetiracetam blocks ethanol-seeking behaviour by inhibiting AMPA receptors [62]. An open-label study suggested the ability of levetiracetam to decrease alcohol withdrawal symptoms [63]. A second open-label study testing levetiracetam $(2000 \mathrm{mg} / \mathrm{d})$ in 20 alcohol-dependent subjects treated for 10 weeks, reported a reduction in alcohol drinking, craving and addiction severity [64]. While double-blind placebo-controlled studies are needed to draw any conclusion, the preliminary evidence highlights the safety of levetiracetam, when administered to $\mathrm{AD}$ individuals.

Given the side effects observed with the majority of iGluRs legands, there is interest in selective mGluRs ligands, which mediate slower, modulatory glutamate neurotransmission [54]. Attenuation of glutamatergic transmission by mGluRs ligands reduces the rewarding and reinforcing effects of ethanol as well as relapse-like behaviours [55]. There are eight different mGluRs, which belong to three groups, based on sequence similarities, preferred signal transduction pathways and pharmacology. Specifically, these groups are Group I (mGluR1 and mGluR5), Group II (mGluR2 and mGluR3) and Group III (mGluR4, mGluR6, mGluR7, and mGluR8) [65]. mGluR5 and mGluR2/3 receptors are widely distributed in meso- 
corticolimbic brain regions associated with drug reinforcement. In particular, there is a high expression of mGluR5 in forebrain and limbic structures (olfactory bulb, anterior olfactory nuclei, olfactory tubercle, dorsal striatum, NAc, lateral septum, hippocampal formation). mGluR5s are located at both presynaptic and postsynaptic sites in the brain and it has been observed that the activation of mGluR5s interacts with ionotropic NMDA receptors, enhancing NMDA responses in striatal projection neurons [66]. This last observation suggests that blockade of mGluR5s could reduce glutamatergic transmission through NMDA receptors. Thus, blockade of mGluR5s could attenuate the state of hyperexcitability induced by glutamatergic excitatory neurotransmission during alcohol withdrawal and abstinence, which may be associated with a high risk of relapse [20,67].

In 1999, Gasparini and colleagues [68] published the structure and initial characterization of a highly potent, non-competitive mGlu5 receptor antagonist, the 2-methyl-6-(phenylethynyl)pyridine (MPEP). Later studies showed that MPEP also acts as an antagonist of the NMDA receptor and inhibits monoamine oxidaseA [69]. The effects of MPEP on voluntary ethanol consumption and relapse behaviour were tested in preclinical studies. MPEP significantly attenuates ethanol seeking in alcohol-preferring rats in a dose-related manner. Moreover, treatment with MPEP (twice a day) resulted in a significant dose-dependent reduction of the alcohol deprivation effect and to a lesser extent, of baseline drinking [70].

A possible explanation for the ability of mGluR5 negative allosteric modulators (NAMs) to reduce ethanol self-administration is that mGluR5 NAMs alter the discriminative stimulus effects of ethanol [71]. The lack of selectivity of MPEP combined with undesirable pharmacological properties (e.g. low water solubility and low brain penetration) led Cosford et al. [72] to develop a new mGlu5R antagonist, the 3-[(2-methyl-1,3-thiazol-4-yl)ethynyl]pyridine (MTEP), which holds a greater selectivity for the mGlu5 receptor and greater bioavailability. MTEP was tested in different rodent models of alcoholism and it reduced alcohol-seeking behaviour, decreasing both the consumption of ethanol and the appetitive response for ethanol [73,74]. The effects of MTEP are associated with regulation of cortical glutamate systems, particularly those in olfactory-related regions [73,74].

Besheer and colleagues [75] suggest that mGluR1 antagonists, unlike mGluR5 antagonists, do not produce alcohol-like interoceptive effects and do not alter the interoceptive effects produced by alcohol. The two receptors mGlu1 and mGlu5 are both located primarily at postsynaptic sites, and share G-protein and cell signalling mechanisms. A functional dissociation between mGlu1 and mGlu5 receptors in the interoceptive effects of alcohol may represent an explanation of the different effects of the antagonism at mGlu1 vs. mGlu5 receptors [75].

Members of the Group II mGlu receptors (mGlu2/3) have also emerged as potential therapeutic targets for treating alcohol AD. Group II agonists have anxiolytic and anticonvulsant properties and preclinical studies demonstrate that mGluR2/3 agonists reduce active drug reinforcement and drug-seeking behaviour [54]. mGlu2/3 receptors are expressed preferentially in mesocorticolimbic brain regions and are located both pre- and post-synaptically. Presynaptic autoreceptor function is implicated in its therapeutic action as $m G l u 2 / 3$ receptor agonists reduce extracellular glutamate levels in the NAc, whereas receptor blockade increases extracellular glutamate [20]. Bäckström and Hyytiä [76] tested the effects of a pretreatment with the mGlu2/3 receptor agonist LY379268 in attenuating alcohol-seeking behaviour and alcohol self-administration in rats. This experiment showed that LY379268, used at different doses $[0,1,3$ and $5 \mathrm{mg} / \mathrm{kg}$ intraperitoneally (i.p.)], attenuated alcohol self-administration and reinstatement at doses that also decreased spontaneous locomotor activity. Of note, similar effects were found for (S)-3,4-DCPG, an antagonist of the mGlu8 receptor (Group III) [76]. Subsequently, Rodd and colleagues [77] demon- strated that LY404039, suppressed reinstatement of ethanol-seeking behaviour induced by cues but not active ethanol self-administration. It has been suggested that the reason for the lack of effect of LY404039 on ethanol self-administration may be the use of a high ethanol-preferring $\mathrm{P}$ rat strain as opposed to outbred rats used in other studies [54]. mGluR2/3 agonists, in particular LY379268, modify ethanol-seeking induced both by stress and exposure to drug-related environmental stimuli, suggesting that mGlu2/3 receptors participate in mediating the effects of contextual stimuli conditioned to drugs [78].

However, some of the above-mentioned effects of mGluR2/3 agonists on drug and ethanol reinforcement or reinstatement must be interpreted with caution, as the effects of mGluR $2 / 3$ agonists on ethanol consumption may not be direct, but secondary to other effects [54].

These data from animal studies suggest that Groups I and II mGluRs may represent promising treatment targets for stress- and cue-induced alcohol seeking and relapse. However, there are no human studies on the efficacy of either Group I mGluR NAMs or Group II mGluR agonists in the treatment of AD.

\section{CORTICOTROPIN-RELEASING FACTOR (CRF) AND CRF-LIKE PEPTIDES}

Stress activates a number of biological systems in order to appropriate a coordinated physiological and behavioural response. Two important biological stress systems, the hypothalamic-pituitary axis (HPA) and the locus coeruleus/norepinephrine system (LC$\mathrm{NE}$ ) interact to exert their coordination of the appropriate behavioural response. Individuals cope with stress differently. Aberrant coping mechanisms in response to stress have been linked to a wide range of psychiatric disorders such as depression, anxiety and drug and alcohol dependence [79,80]. In particular, the stress response has not only a key role in the development and facilitation of alcohol and substance abuse disorders [81], but it is also implicated in a behavioural component of alcohol relapse [82].

Corticotropin-releasing factor (CRF) also called corticotropinreleasing hormone $(\mathrm{CRH})$, represents one of the most intensively studied stress-related peptides in the field of addictions. CRF is a 41 amino acid peptide, secreted from the paraventricular nucleus (PVN) of the hypothalamus in response to stress. CRF is expressed in neuroanatomical regions associated with substance abuse and reward such as the central nucleus of amygdala (CeA) [83], the LC and the hypothalamus. Moreover, CRF appears to link two of the main stress response systems, namely the HPA-axis and the LC-NE system. This suggests a central role for CRF in coordinating and controlling many of the different afferents of the biological stress pathways and their role in substance abuse. [82-84]. Preclinical studies demonstrate that acute ethanol withdrawal increases CRF levels in the CeA [85] and in the bed nucleus of the stria terminalis [86] mediating stress and anxiety responses. These responses are reversed by non-selective CRF antagonist administration [87]. CRF exerts its effects on cells by binding the CRF1 and CRF2 receptors [88], which are members of the 7 transmembrane G-protein coupled receptor family. CRFR1s are found at high levels in the cerebral cortex, cerebellum, amygdala, hippocampus and olfactory bulb [89] and mediate anxiogenic properties of CRF and the coordination of the stress response [90]. In fact, CRFR1 null mice show decreased anxiety like behaviour and display an impaired stress response [91]. The role of the CRFR2 still remains controversial, as there is evidence from animal models suggesting CRFR2 antagonists have an anxiolytic effect [92], however CRFR2 null mice display an anxiogenic phenotype [93].

In the genetically selected msP rats, high alcohol preference has cosegregated (the mutated gene and the disease are transmitted together to the next generation) with increased behavioural sensitivity to stress, creating a phenocopy of the postdependent phenotype. For example, Hansson et al. [94] identified a genetic variant in the 
promoter region of CRFR1, which resulted in higher CRFR1 expression in several brain regions of the $\mathrm{msP}$ line and was associated with increased sensitivity to relapse into alcohol seeking induced by environmental stress [94]. In the same animal model, Hansson et al. [94] measured CRFR1 transcript in CeA, medial nucleus of amygdala (MeA) and NAc after two weeks of exposure to alcohol. In these areas, a down regulation of CRFR1 transcript was found, suggesting that alcohol could be voluntarily consumed by these animals partially for the ability of alcohol to reduce CRFR1 activity [95].

Similarly, an upregulation of the CRFR1 transcript was present within the basolateral and medial amygdala in genetically nonselected rats following a history of dependence. This upregulation probably contributed to their behavioural phenotype with elevated voluntary alcohol consumption and potentiated stress sensitivity during protracted abstinence. Moreover CRFR1 antagonism eliminated this increased behavioural sensitivity to stress in the postdependent state [96].

In addition to the large body of evidence that upregulated activity of the CRF system confers susceptibility for excessive selfadministration of alcohol and relapse, there are also data linking genetic modulations of CRF receptors to drinking behaviour in humans. For example, two tagging SNPs (htSNPs) of the CRF1 gene, rs242938 and rs1876831, were analyzed in a cohort of adolescents with little previous exposure to alcohol and a cohort of AD adults [97]. This study linked genetic polymorphisms in CRF1 to risky-drinking behaviour in adolescents. In fact, there was an association of SNPs rs 242938 and rs1876831 with binge-drinking, lifetime prevalence of alcohol intake and lifetime prevalence of drunkenness. In addition, the authors found an association between rs1876831 and high amount of drinking in AD adults. Blomeyer et al. [98] measured the effects of negative life events on the amount of drinking in the same cohort of adolescents genotyped for CRF1 htSNPs by Treutlein et al. [97]. In this study, the C allele of htSNP rs 1876831 was associated with drinking more alcohol per occasion and increased lifetime rates of heavy drinking, and this was mediated by the number of negative life events in the last 3 years [98].

While more research is needed to confirm this finding, the impact of stress on heavy drinking could be more evident among individuals carrying a particular genotypic variant of CRF1 gene. It is possible that these CRF1 polymorphisms [97] may be predictive of response to CRF1 antagonist treatment for alcoholism, an intriguing pharmacological approach to treat AD. The CRF1 receptor seems to mediate the enhancement in ethanol self-administration during abstinence period in $\mathrm{AD}$ models like $\mathrm{C} 57 \mathrm{BL} / 6 \mathrm{~J}$ mice. In fact, the increase in ethanol self-administration is less in CRFR1 knockout mice after dependence induction. Moreover, the CRF1 antagonist antalarmin reverses the enhanced self-administration in this animal model [99]. CRF1 antagonists selectively reduce excessive selfadministration of ethanol in alcohol dependent rats also during acute withdrawal, while the same antagonism has no effect on ethanol self-administration in nondependent animals [100].

Another CRF1-receptor antagonist, (N,N-bis(2-methoxyethyl)3-(4-methoxy-2-methylphenyl)-2,5-dimethylpyrazolo[1,5a]pyrimidin-7-amine), MPZP, blocked dependence-induced increases in alcohol drinking by $\mathrm{P}$ rats without affecting operant alcohol responding in nondependent controls [101].

The newly synthesized CRF1R antagonist 3-(4-Chloro-2morpholin-4-yl-thiazol-5-yl)-8-(1-ethylpropyl)-2,6-dimethyl-

imidazo[1,2-b]pyridazine (MTIP) is a novel, orally available and brain-penetrant CRFR1 antagonist, which showed in vivo activity in preclinical models of alcoholism. Compared to other wellcharacterized CRF1R antagonists, MTIP had a markedly reduced volume of distribution and clearance. MTIP blocked excessive alcohol self-administration in Wistar rats with a history of dependence, as well as in a genetic model of high alcohol preference, the
msP rat, at doses that had no effect in nondependent Wistar rats. Also, MTIP blocked reinstatement of stress-induced alcohol seeking both in postdependent, and in genetically selected msP animals, again at doses that were ineffective in nondependent Wistar rats [102,103].

Recent studies indicate that CRF is not the sole ligand of CRF receptors, and that the endogenous neuropeptides urocortin 1 (Ucn1), urocortin 2 (Ucn2, also known as stresscopin related peptide) and urocortin 3 (Ucn3, also known as stresscopin) also bind these receptors [104-106]. Moreover, these studies show that all three urocortins have a higher affinity than CRF at CRFR2. CRFR2 is currently under investigation in AD. The lateral septum (LS) and dorsal raphe (DR) are major loci of CRFR2s [106].

Ucn 1 binds both CRF receptors with the highest affinity. Ucn1 in the brain is primarily expressed in the perioculomotor urocortincontaining population of neurons (pIIIu), a brain region thought to be only involved in ocular function [107]. The projections from the non-preganglionic Edinger-Westphal (npEW) nucleus include a large number of brain regions. The most prominent projections include the LS, the DR and spinal cord $[108,109]$.

Although the regulation of Ucn 1 expression is not completely studied or understood, results from the majority of inducible transcription factors (ITFs) mapping studies indicate that the npEW is one of the brain areas most sensitive to ethanol, and that it is persistently activated following repeated alcohol self-administration [110-121]. In summary, in animal models the Ucn1/CRF2 receptor system expression seems to be modified by prolonged ethanol exposure suggesting that this system may be involved in behavioural changes related to $\mathrm{AD}[122]$.

The Ucn 1 system is not only sensitive, but also may be involved in the genetic predisposition to high alcohol intake, as a number of studies evaluating the Ucn 1 strains levels show higher Ucn 1 measures in rodent lines selectively-bred to prefer alcohol versus alcohol avoiding rats [123-128].

Furthermore, manipulations of the Ucn1 neurocircuit modulate alcohol consumption and sensitivity. Mice with successful npEW lesions were compared to sham-operated controls and dramatic effects of these lesions on alcohol consumption were observed. Mice with npEW lesions significantly reduced their preference for alcohol when exposed to a choice between water and $3 \%, 6 \%$ or $10 \%$ ethanol [129].

The Ucn1/CRF2 neurocircuits have no apparent connections to the mesolimbic DA system and the amygdala. Moreover, while the DA system is thought to play an important role in the appetitive phase of reinforcement [130], there is no evidence for the involvement of the Ucn 1 system. Therefore, it is more likely that the npEW is involved in regulation of ethanol intake through effects on the consummatory phase of reinforcement. This regulation is most likely to occur through from the npEW to other brain regions. LS could be a target of npEW projections, which are involved in the regulation of this behaviour. Recent studies show that Ucn 1 acts to depress glutamatergic transmission in the LS through CRFR2 [131132]. These studies lead to hypothesize a simplified neurocircuit in which activation of the npEW by ethanol leads to inhibition of activity of the LS (perhaps through inhibiting the glutamatergic excitation of this brain area). Since LS neurons are primarily GABAergic, their inhibition by Ucn would lead to disinhibition of hypothalamic target brain regions, and thereby increased to consumption of available fluids like ethanol. Clearly, additional studies are needed to fully address this hypothesis. One of the missing links in this scheme is the location of hypothalamic brain regions disinhibited through LS, and contributing to fluid intake. The hypothalamus is a long-proposed integrator of consummatory responses, but hypothalamic subregions affected by ethanol have not been mapped in sufficient detail [133]. A recent study by Ryabinin et al. [134] confirmed the importance of Ucn 1 innervation and in particular of the 
LS in the regulation of alcohol consumption. In a series of experiments the authors injected Ucn 1 or CRF bilaterally at various doses into the lateral septum of male C57BL/6J mice and immediately after the injection tested ethanol consumption. The authors used a limited access procedure, which takes advantage of higher levels of activity, fluid and alcohol consumption that are observed in mice during early hours into the dark portion of the circadian cycle. Injection of Ucn 1 into the LS of C57 mice significantly attenuated ethanol consumption both in the expression phase of ethanol drinking and during the acquisition phase of alcohol consumption [134].

One potential explanation for this apparent discrepancy is that if Ucn1 contributes to a reward signal associated with ethanol, exogenous application of Ucn 1 could signal that the reward already has been achieved, resulting in no further effort to obtain it (by alcohol consumption). As an alternative explanation, since pIIIu neurons contain other peptides besides Ucn 1 as potential regulators of the rewarding properties of drugs of abuse, it is possible that synergistic actions of these peptides are needed to increase the rewarding properties of alcohol [134]. It is important to note that Ucn3 innervates the same brain structures and alcohol consumption may also be regulated by this peptide. In particular the treatment of AD rats with urocortin III reduced anxiety and ethanol self-administration in the early stages of withdrawal [135].

Although this emerging evidence strongly suggests that CRF receptors represent key pharmacological targets for $\mathrm{AD}$, a clinical concern and potential limitation is that CRF1 and CRF2 agents might have undesirable hormonal and affective side effects, like impaired stress responses and abnormal anxiety-like behaviours [136-138].

\section{NEUROPEPTIDE Y (NPY)}

Neuropeptide Y (NPY) is a 36-amino acid peptide that is expressed at high levels within the mammalian nervous system. NPY is one of the most abundant neuron modulators in the CNS and is considered an important regulating factor in emotional behaviour. For example, administration of exogenous NPY has anti-anxiety and sedative effects that rely, at least partially, on activation of Y1 receptors in the amygdale [139-141]. The effects of NPY are mediated by G-protein-coupled receptors, of which there are currently four subtypes identified: Y1, Y2, Y4, and Y5with Y1 and Y2 receptor subtypes found at significant levels in the CNS. Antidepressantlike actions of NPY have been reported in rats [142], and Y1- receptors seem to mediate this effect [143-144]. NPY-Y2 receptors also play a role in the regulation of emotion, as they are located presynaptically on NPY-ergic neurons and control the release of endogenous NPY [145].

In animal models, acute and repeated stress exposure induces different effects in the central expression of NPY. An acute stressor significantly decreases NPY expression in the amygdala, an effect that is concurrent with the anxiogenic effects of stress. On the contrary, when the stressor is repeated, NPY expression is increased in the amygdala, correlated to a behavioural adaptation of stress [146147]. As a consequence, NPY expression seems to be involved in the behavioural adaptation to stressors [146-147].

Using genetically modified mice, NPY levels were inversely related to ethanol intake [148]. As NPY levels are lower in the CeA and MeA of alcohol preferring $(\mathrm{P})$ rats compared to non $\mathrm{P}(\mathrm{NP})$ rats, NPY infusion normalizes the decreased expression of NPY in the CeA phosphorylation and attenuates the anxiety-like and alcohol drinking behaviours of $\mathrm{P}$ rats. Thus, a deficiency in NPY signaling in the CeA may be involved in regulating both anxiety and alcohol drinking behaviours [149] and that NPY system modifications can influence ethanol intake [150-153]. Notably, intraamygdala administration of a viral vector designed to over-express NPY was found to have anxiolytic-like properties and to suppress ethanol intake in rats [154]. Moreover, intracerebroventricular (i.c.v.) infusion of NPY in rats has the ability to prevent stress- induced relapse, by blocking, dose-dependently, the reinstatement of alcohol seeking induced by a pharmacological stress (yohimbine i.p.) [155]. Together, these preclinical studies suggest that in particular the NPY-Y1 receptor, may represent a novel pharmacological target for alcoholism. Research has also focused on the possibility of the Y2 receptor to affect alcohol drinking. For example, the Y2 antagonist BIIE0246 suppresses alcohol intake in both naive [156] and postdependent animals [157].

In summary, targeting the NPY system, possibly through antagonism at presynaptic Y2 autoreceptors, may offer an attractive strategy for developing novel antidepressant and anti-anxiety treatments that may also affect ethanol intake.

\section{NOCICEPTIN}

Nociceptin, also called Orphanin FQ (N/OFQ), is a 17-aminoacid peptide that shows structural homology with opioid peptides, particularly dynorphin A [158]. N/OFQ has a high affinity with the opioid receptor-like 1 (ORL-1), now included in the opioid receptor family and renamed the NOP receptor (nociceptin/orphanin peptide receptor). N/OFQ and its receptor are widely distributed in the $\mathrm{CNS}$, including areas involved with the neurobiology of addictions. N/OFQ has been found to act in the brain as a functional antiopioid peptide by blocking opioid-induced supraspinal analgesia [159160], morphine-induced conditioned place preference [161], and morphine induced increases in extracellular DA levels in the NAc [162]. Moreover, N/OFQ inhibits stress-induced ethanol seeking and exerts general anti-stress-like effects by acting as a functional antagonist of extrahypothalamic CRF transmission [163].

Genetic variants of the N/OFQ and NOP genes may be linked to vulnerability for alcoholism. One study revealed a link between alcoholism and two SNPs in the N/OFQgene [164]. Moreover, the SNP rs6010718 of the gene encoding the NOP receptor was associated with the diagnosis of AD in a Scandinavian sample [165].

Several studies demonstrate that N/OFQ regulates ethanol preference, ethanol reward, and ethanol-seeking behaviour. For example, activation of NOP receptors by N/OFQ inhibits home cage ethanol drinking and operant ethanol self-administration. N/OFQ also reduces both ethanol-induced conditioned place preference and conditioned reinstatement of alcohol seeking [166-168]. Moreover, N/OFQ inhibits stress-induced ethanol seeking and exerts general antistress effects by acting as a functional antagonist of extrahypothalamic CRF transmission [169-170]. Studies using alcohol preferring $\mathrm{msP}$ rats demonstrated that subchronic administration of N/OFQ or N/OFQ analogs significantly reduce ethanol selfadministration [171-172]. By contrast, in nonselected Wistar rats tested under the same experimental conditions, N/OFQ did not alter ethanol consumption [173]. Studies with in situ hybridization revealed higher expression levels of N/OFQ and NOP receptor mRNA in numerous brain areas of msP compared to Wistar rats [173].

Recent data show that the opioid agonist/partial agonist buprenorphine reduces alcohol intake in $\mathrm{msP}$ rats via activation of NOP receptors [174]. This last observation not only strengthens the link between N/OFQ and excessive alcohol consumption, but also suggests potential clinical applications. This is consistent with the observation that buprenorphine reduces not only opiate use but also alcohol intake in heroin dependent subjects [175]. In summary, these data provide the rationale for the development of N/OFQ receptor agonists as new pharmacotherapies for the treatment of $\mathrm{AD}$.

\section{SUBSTANCE P AND NEUROKININ 1 (NK1) RECEPTOR}

Substance $\mathrm{P}$ (SP) is an 11 amino acid peptide [176] involved in $\mathrm{C}$-fiber sensory transmission wherein blockade of the transmission of SP produces analgesic and anti-inflammatory effects [177]. Substance $\mathrm{P}$ and its receptor Neurokinin 1 receptor (NK1R) are highly expressed in brain regions involved in drug reward and affective 
behaviours (for review see [178]). NK1R agonists have anxiogeniclike effects and cause conditioned place aversion. Conversely, NK1R antagonists produce anxiolytic-like and antidepressant-like effects [178] as human studies demonstrate that antagonism of SP or of NK1R to be effective for depression or anxiety [179-181]. Despite this early evidence of efficacy in treating affective disorders by NK1R antagonists, no further studies were published.

More recently, there has been an interest in the role of NK1R as a potential pharmacological target for alcoholism. This interest was based on the preclinical evidence that genetic deletion of NK1R suppresses alcohol intake [182]. Conversely, inactivation of NK1R but not NK1R antagonism critically seems to modulate alcohol reward and escalation of alcohol intake following multiple deprivations, two important characteristics of addiction.

In humans, a recent study tested the high-affinity selective NK1R antagonist LY686017, a compound characterized by oral availability and brain penetrance [183]. LY686017 was administered daily to 50 recently detoxified patients with a diagnosis of AD and with high trait anxiety [Spielberg Trait Anxiety Inventory Test (STAI) > 39]. LY686017 was administered at the dose of $50 \mathrm{mg}$ daily, which yields a >90\% blockade of central NK1R. LY686017 was significantly more effective than placebo in suppressing spontaneous alcohol craving, improving overall well-being, blunting cravings induced by a laboratory challenge procedure, and attenuating cortisol response. Finally, an examination of allelic variations in the NK1R gene in 271 alcoholic subjects and in 337 healthy controls found that the development of AD in Caucasian individuals is significantly associated with some polymorphisms of the NK1R gene [184].

In summary, preclinical and clinical evidence suggest that NK1R antagonism might be of therapeutic value in alcoholism. Future studies will have to identify the best population responding to NK1 R antagonism. In this regard, considering that Substance P acts at NK1Rs to mediate both behavioural stress responses and drug reward mechanisms, the NK1R antagonist aprepitant is currently under investigation for the treatment of alcoholics with Posttraumatic Stress Disorder (PTSD) co-morbidity (NCT00896038).

\section{NEUROKININ B AND TACHYKININ RECEPTORS}

Similar to NK1 receptors, tachykinin receptors 3 (NK3Rs), the receptors for the tachykinin 3 peptide (neurokinin B) are involved in drug reward mechanisms. In particular, it was hypothesized that NK3R agonists reduce ethanol consumption by replacing the rewarding properties of alcohol, thus making alcohol consumption redundant [185, 186]. A preclinical study in Sardinian preferring and non-preferring rats reported that administration of the selective NK3R agonist senktide inhibits alcohol intake, without affecting overall water or food intake $[187,188]$. The brain regions that were highly sensitive to the inhibitory effect of the tachykinin NK3R agonists were the lateral hypothalamus and the nucleus basalis magnocellularis [189].

Because of mouse, rat and human species differences in the NK3R, no clinical trials have been carried out to evaluate the efficacy of NK3R agonists in reducing ethanol consumption in humans [190]. However, a recent study within the Collaborative Study on the Genetics of Alcoholism (COGA) found evidence of an association between a variation in TACR3 gene and susceptibility for AD [190]. TACR3 belongs to a family of genes that encode proteins that function as receptors for tachykinins (including NK3R for neurokinin B). Interestingly, a secondary analysis showed that variation in TACR3 was associated with more severe alcoholism [190].

Unlike NK1 and NK3 receptors, tachykinin NK2 receptors are not highly abundant in the CNS, although NK2 receptor mRNA and NK2 receptor binding sites have been identified in the human brain [191]. The selective NK2R antagonist saredutant (SR48968) s has anxiolytic- and antidepressant-like activities [192]. However,
NK2Rs seem to be less involved in reward processes. For example, a study by Ciccocioppo and colleagues [193] showed that the NK2 selective agonist GR 64349, unlike the NK3 selective agonists, did not inhibit alcohol intake in Sardinian alcohol-preferring rats. However, no further studies have been conducted to confirm these findings.

\section{NEUROPEPTIDE $S$}

The 20 amino-acid peptide Neuropeptide S (NPS) and its receptor NPSR were first identified in 2004, as a novel transmitter system, mainly expressed in the brain [194]. NPS is co-expressed with excitatory transmitters such as glutamate, acetylcholine or CRF. While the projection areas of these NPS-producing neurons are currently unknown, however, outside of the CNS, the NPS precursor is expressed mainly in endocrine tissues [195]. The NPSR is a typical member of the G-protein-coupled receptor superfamily and is expressed in brain areas involved in olfactory processing, in brain areas critical for fear processing (e.g. amygdala and paraventricular nuclei of the hypothalamus), as well as in brain regions involved in sleep-wake modulation (e.g. thalamic intralaminar nuclei, preoptic nucleus or tuberomammillary nucleus). Thus, the NPS system mediates specific effects on synaptic transmission to and within the amygdala, which are important for processing of acute fear as well as extinction of fear memories [196]. Ruggeri et al. [197] investigated the variations of NPSR mRNA expression in rats exposed to 6 days of intermittent ethanol intoxication and demonstrated an increased NPSR mRNA expression in different brain areas of postdependent rats. Central activation of NPS receptors facilitates relapse to alcohol seeking. Thus, considering that postdependent rats are more inclined to relapse, one could speculate that this over expression may also be functionally relevant in alcohol drinking [198]. Another recent experiment sought to determine whether the NPS system might play a role in the regulation of alcohol-related behaviours [199]. This study showed that i.c.v. NPS does not modify ongoing ethanol self-administration in rats, indicating that motivational circuitry of ethanol reinforcement is not directly affected by activation of NPSR. On the other hand, recent data by BadiaElder et al. [200] showed that i.c.v. NPS injection signifi-cantly reduces ethanol drinking in genetically selected alcohol preferring $\mathrm{P}$ rats. Experimental design differences may explain the discrepant results of the two studies. Badia-Elder et al. [200] tested the effect of NPS on home cage voluntary ethanol drinking, whereas Cannella et al. [199] studied peptide effects under operant conditions. Operant self-administration is thought to more directly gauge motivation to obtain the reinforcer, whereas home cage drinking can also be controlled by taste, calories and other factors not directly related to pharmacological reinforcement. Furthermore, the P rats show elevated anxiogenic-like behaviour and it has been hypothesized that their excessive ethanol drinking is in part driven by reduction of anxiety symptoms. Notably, NPS has anxiolytic-like effects in animal models of anxiety [201, 202].

Moreover, Cannella and collegues [199] showed a three-fold increase of relapse in rats subjected to repeated reinstatement testing. As the lateral hypothalamus $(\mathrm{LaH})$ is traditionally implicated in reward and motivation and is one of the brain areas with the highest NPSR transcript expression levels, Canella et al. [199] demonstrated that intra-LaH administration dramatically reinstated extinguished ethanol responding suggesting that the $\mathrm{LaH}$ is an important brain site of action for NPS effects on alcohol relapse.

\section{GALANIN}

Galanin is a feeding-stimulatory peptide with neuroprotective effects. In fact, increased galanin concentrations seem to have neuroprotective effects and promote neurogenesis [203]. The three galanin receptors (GalR1, GalR2, GalR3), are involved, centrally, in the control of feeding, alcohol intake, seizure threshold, cognitive performance and mood, and peripherally, in the control of pain 
threshold [203]. Both human genetic and behavioural animal studies have suggested that galanin may be involved in addictive behaviours, such as repeated alcohol intake. Earlier studies showed that hypothalamic injection of galanin increases the release of DA in the NAc, just as systemic alcohol does [203]. In humans, a genetic study found a significant association between the single nucleotide polymorphism (SNP) rs3091367 of the GalR3 and alcoholism, suggesting that galanin's influence on alcoholism vulnerability may be mediated mainly through GalR3 [204]. This finding suggests that the development of galanin receptor ligands, in particular GalR3 antagonists, might be useful in the treatment of $\mathrm{AD}$.

\section{GHRELIN}

Ghrelin is a 28-amino acid gut peptide with an n-octanoylation modification at Ser 3 [205]. Ghrelin acts as the endogenous ligand for the growth hormone secretagogue receptor (GHS-R), a Gprotein coupled receptor that induces growth hormone $(\mathrm{GH})$ release from the pituitary [205]. Ghrelin's discovery was related to its ability to stimulate GH release. Subsequently, it has clearly demonstrated that ghrelin affects food-seeking behaviour, stimulating appetite and food intake. Ghrelin stimulates appetite by acting on the hypothalamic arcuate nucleus (ARC), a region that controls the intake of food and other substances, including alcohol. Opioidergic neurons, which play a role in the reinforcing effects of alcohol, also are located in the ARC [206]. In addition to the ARC, GHS-Rs are also highly expressed in the caudal brain stem, the VTA, hippocampus, substantia nigra, and dorsal and medial raphe nuclei [207, 208]. The expression of the GHS-R in the mesolimbic DA pathway suggests that ghrelin could also modulate the hedonic properties of food and the so-called reward system [209,210]. This hypothesis has been tested in animals. Intracerebral ventricular (i.c.v.) ghrelin administration into the third ventricle increases extracellular concentrations of accumbal DA in NMRI mice [209], also showing that ghrelin activates the cholinergic-dopaminergic reward link and that ventral tegmental nAChRs have a central role for the DA-enhancing properties of ghrelin. A second set of experiments extended the previous results, injecting ghrelin directly into the VTA [211]. These findings were replicated when ghrelin was injected peripherally [212]. A more recent set of experiments used an elegant approach of genetic (GHS-R1A knockout mice) and pharmacological (two GHS-R1A antagonists: BIM28163, delivered i.c.v; and JMV2959, i.p.) models of suppressed ghrelin signaling [213]. These experiments demonstrated that: i) alcohol-induced brain reward parameters, such as enhanced extracellular accumbal DA overflow, locomotor stimulation and conditioned place preference (CPP) were consistently abolished or attenuated by two GHS-R1A antagonists in wild-type mice and were abolished in GHS-R1A knockout mice; ii) i.c.v. administration of ghrelin to mice significantly increased alcohol consumption compared to vehicle treatment in a 2-bottle (alcohol/water) free choice limited access paradigm. Bilateral administration of ghrelin into either the VTA or the LDTg also increased alcohol consumption in comparison to vehicle. The percentage increase in alcohol consumption was significantly greater following administration to the VTA or the laterodorsal tegmental nucleus (LDTg) compared to the i.c.v. route. Food intake (normal chow) was increased by i.c.v. ghrelin administration in comparison to vehicle but was not affected by bilateral ghrelin administration into either the VTA or the LDTg. Alcohol intake in the 2-bottle (alcohol/water) free choice limited access paradigm was suppressed in mice by both the GHS-R1A antagonists (delivered either i.c.v. or i.p.). The effects of i.c.v. ghrelin on alcohol intake were absent in GHS-R1A knockout mice.

Human studies also shed light on the acute effects of alcohol on ghrelin as well as on the possible role of ghrelin in alcohol-seeking behaviour. In alcoholics, alcohol is able to acutely inhibit ghrelin secretion and plasma ghrelin levels correlate with psychometric determinations of the alcohol seeking behaviour, such as alcohol craving (for review, see [214]).
Together, these findings suggest that ghrelin system plays a role in $\mathrm{AD}$, thus representing a new possible pharmacological target.

\section{GLIAL CELL LINE-DERIVED NEUROTROPHIC FACTOR (GDNF)}

The glial cell line-derived neurotrophic factor (GDNF) is a distant member of the transforming growth factor $\beta$ superfamily that was originally isolated from the rat B49 glial cell line. High levels of the growth factor are found in the striatum (dorsal striatum and NAc), thalamus, cortex and hippocampus. The major source of GDNF in the midbrain is the striatum where GDNF is retrogradely transported by dopaminergic neurons of the substantia nigra pars compacta (SNc) and the VTA [215]. GDNF plays an essential role in the development and survival of motor neurons, in the synaptogenesis and is an essential factor for the maintenance and survival of adult DA neurons. Moreover GDNF seems to regulate neuronal excitability and transmitter release [216].

Dopaminergic neurons within the VTA are a critical component of the neural circuitry implicated in addictive behaviours [217]. GFR $\alpha 1$ and transfection receptor (Ret) are highly expressed in VTA dopaminergic neurons and increasing evidences suggest that GDNF plays a regulatory role in the actions of drugs of abuse, including ethanol.

Recent studies showed that GDNF inhibits ethanol-drinking behaviours. A single administration of GDNF into the VTA of rats results in a rapid reduction of operant self-administration of ethanol [218,219]. Moreover the administration of GDNF into the VTA reduces consumption of moderate levels of ethanol in a paradigm that resembles social drinking [218,219]. On the other hand, in models of excessive and "binge-like" drinking of ethanol (i.e. using a $20 \%$ ethanol solution), GDNF infusion in the VTA also reduces ethanol consumption by lever presses $[219,220]$.

Considering an animal model of relapse, Carnicella and collegues [219] found that activation of GDNF pathway in the VTA reduces self-administration of ethanol. Together, these results suggest that GDNF is a potent, rapid inhibitor of excessive consumption and relapse to ethanol.

The main signaling pathways activated via GDNF-mediatedRet activation are the MAPK, PI3K and PLC $\gamma$. In the VTA, a specific inhibition of MAPK blocked GDNF-mediated reduction in ethanol self-administration [219]. Thus, the MAPK seems the specific signalling pathaway by which GDNF mediates a reduction in ethanol-drinking behaviours. GDNF rapidly inhibits the activity of A-type $\mathrm{K}+$ channel currents in primary midbrain neurons via a mechanism that requires the activation of the MAPK pathway [221]. Therefore, it is possible that GDNF, via the inhibition of an A-type $\mathrm{K}+$ channel, alters the excitability of the neurons in the VTA, leading to the decrease in ethanol self-administration.

On the other hand, the long-lasting actions of GDNF may be explained by GDNF-induced transcriptional changes, that could persist beyond the activation and termination of GDNF signaling. [222]. Moreover GDNF upregulates its own expression, leading to a prolonged activation of the GDNF signaling pathway [223]. In addition, several studies suggest a role for GDNF in the regulation of tyrosine hydroxylase (TH), the rate-limiting enzyme in the biosynthesis of DA in the midbrain [220]. Upregulation of TH levels has been reported as one of the hallmarks of biochemical adaptations to in vivo chronic exposure to drugs of abuse, including ethanol [224].

All these data suggest that GDNF plays an important role in controlling ethanol drinking behaviours and suggest that upregulation of the GDNF pathway may be an approach to treat AD. However, it is unlikely that GDNF itself could be used as a therapeutic agent considering that it cannot cross the blood-brain barrier [225]. Some recent studies suggest the possible use of small molecules that increase the production of GDNF or activate its receptors. 
There are several small molecules that have been reported to increase the expression of GDNF or activate the GDNF signalling pathway. Ibogaine is a natural alkaloid reported to reverse the adverse actions of multiple drugs of abuse including alcohol [226]. Systemic administration of ibogaine in rats reduces ethanol selfadministration and relapse and increases GDNF expression, resulting in the activation of the GDNF pathway [227]. Importantly, the actions of ibogaine in reducing ethanol intake were localized into the VTA, and infusion of anti-GDNF neutralizing antibodies into the VTA attenuated the ibogaine-mediated decrease in ethanol selfadministration [227]. Despite its attractive properties, ibogaine can induce severe side-effects such as hallucinations, whole-body tremors and ataxia that may be related to neurotoxicity in the cerebellum and dysregulation of the cardiovascular system [226].

A potential strategy to overcome these undesirable actions of ibogaine is the use of derivatives like noribogaine and 18-methoxycoronaridine (18-MC). 18-MC was found to reduce ethanol intake in rodents, without affecting water consumption [228]. Importantly, these ibogaine-derived metabolites have no tremorigenic effects or evidence of cerebellar toxicity in animals [228].

Cabergoline, a D2-like receptor agonist, increases GDNF expression and secretion in cultured astrocytes [229]. Systemic administration of cabergoline significantly reduces operant ethanol self-administration in rats [230]. Moreover, systemic administration of cabergoline reduced both the reacquisition of operant responding for ethanol after a period of extinction and cue-induces ethanolseeking after abstinence (which represents two different models of relapse) [230]. These results suggest that cabergoline decreases ethanol-drinking and ethanol-seeking behaviours, and that these effects are mediated by the upregulation of the GDNF pathway in the mesolimbic system. Thus, cabergoline deserves future investigations as a new alcohol pharmacotherapy [220].

\section{ACETALDEHYDE (ACD)}

Three main enzymatic pathways, namely alcohol dehydrogenase (ADH), cytochrome P4502E1 (CYP2E1) and catalase, metabolize ethanol to acetaldehyde (ACD). Acetaldehyde, the first product of ethanol metabolism, plays a key role in the toxic effects of ethanol and has also been identified as a potential psychoactive drug able to induce some behavioural effects. It has been proposed that ACD is a key mediator of ethanol's neuropharmacological and behavioural effects. Although controversial and not fully accepted, according to this hypothesis, ethanol would be a mere pro-drug whose effects are fully mediated by its first metabolite ACD [232]. Thus, a number of behavioural studies focused on ACD reinforcing properties and demonstrated that ACD self-administration is much easier to establish than ethanol self-administration [232, 233]. Thus, it was proposed that ACD is a stronger reinforcer than its parent drug ethanol. Recently, ACD was similarly shown to be a 1000 -fold more potent reinforcer than ethanol when tested for selfadministration into the VTA, a brain region strongly involved in ethanol reinforcing effects [234]. The reinforcing properties of ACD were also confirmed in place conditioning studies [235,236]. Notably, this place preference was stronger in rats genetically selected for their high ethanol preference [237]. Moreover ACD selfadministration increased subsequent voluntary alcohol consumption in a free choice procedure [238,239].

These data support the hypothesis that ACD participates in ethanol's psychoactive effect through its own rewarding properties. Acetaldehyde seems to have a key role as a mediator of the mesolimbic DA-stimulating effects following ethanol ingestion. In fact, in animal models both ethanol and ACD administration increase NAc DA release [240].

Consistent with in vivo reports, in vitro studies confirmed a crucial role of ACD in alcohol induced activation of midbrain DA cells. When ACD formation is prevented, ethanol ceases to enhance the spike frequency of DA neurons, suggesting that ACD mediates ethanol-induced effects on DA neuronal spontaneous activity. Further evidence is provided by the observation that ACD dose dependently produces a fast increase in DA neuronal firing activity [240242]. Cysteine, (2R)-2-amino-3-sulfanyl-propanoic acid, is not an essential amino acid with a thiol side chain. Cysteine is efficacious to bind ACD derived from alcohol drinking to prevent the possible role of ACD in digestive tract cancer [243-245], alcoholic cardiomyopathy [246], as well as to prevent ACD chronic toxicity [247] and oxidative damage [246]. In Wistar rats, pretreated i.p. with saline or L-cysteine, followed by intragastric administration of saline, ethanol , or ACD, L-cysteine dose-dependently prevented both ethanol and ACD-induced conditioned place preference [248]. In the same animal model, pretreatment with L-cysteine reduced both acquisition and maintenance of oral ethanol self-administration behaviour [249]. In addition, pretreatment with L-cysteine reduced reinstatement of ethanol-drinking behaviour after an oral ethanol extinction [249]. These experiments show that L-cysteine reduces all phases of oral ethanol self-administration. The efficacy of Lcysteine on relapse to alcohol drinking represents an interesting pharmacological approach and could lead to new alcohol pharmacotherapies [249].

\section{KUDZU}

Several genetic and clinical observations indicate that a selective deficiency of aldehyde dehydrogenase 2 (ALDH-2) is often associated with reduced drinking and risk for alcoholism [250]. Subjects with ALDH-2 deficiency, such as 15 to $40 \%$ of Southeast Asians, have an inactivation of ALDH-2 due to an E487K mutation [251]. These individuals, after taking alcohol, experience unpleasant symptoms due to the accumulation of ACD [250]. Acetaldehyde is a product of hepatic alcohol dehydrogenase (ADH) and is metabolized to acetate by cytoplasmic ALDH-1 and mitochondrial ALDH-2.

It was suggested that administration of drugs that inhibit ALDH activity and consequently, induce elevations in ACD, discourage alcoholics to continue drinking. It should be noted that although low levels of brain ACD may be reinforcing in the VTA, high systemic concentrations of ACD are aversive, producing nausea, diaphoresis and tachycardia. The most studied drug with this mechanism of action is the FDA-approved medication disulfiram (see [10]), a nonspecific toxic and irreversible inhibitor of both mitochondrial ALDH-2 and cytoplasmic ALDH-1 [252]. However, disulfiram may have non-specific toxicity caused by chelating metals and reacting with sulfhydryl groups to inactivate diverse proteins and other enzymes, in addition to ALDH-1 and ALDH-2. Thus, research has focused on identifying more selective inhibitors of mitochondrial ALDH-2. Kudzu and kudzu extracts have been identified as such compounds. Kudzu is a perennial leguminous vine of the genus Pueraria lobata native to eastern Asia [253]. Puerarin, daidzin, and daidzein are three of the major isoflavonoid compounds isolated from the extract of Pueraria lobata [253]. The anticraving and "antidrunkeness" effects of extracts of Pueraria lobata have been known to traditional Chinese Medicine for centuries, but its true efficacy and the mechanism(s) of action of its active principle(s) were unproven.

Daidzin was first shown to suppress ethanol intake in ethanol preferring Syrian golden hamsters [254]. Subsequently, it was found that all three isoflavonoid compounds were effective in suppressing voluntary alcohol consumption in alcohol-preferring $(\mathrm{P})$ rats. In particular, daidzein, daidzin, and puerarin, orally administered to $P$ rats at a dose of $100 \mathrm{mg} / \mathrm{kg} /$ day, decrease ethanol intake by $75 \%, 50 \%$, and $40 \%$, respectively [255]. The efficacy of Pueraria lobata extracts in reducing voluntary alcohol consumption has been confirmed in all ethanol-drinking animals tested to date [256260]. The most recent preclinical study tested the efficacy of a highly selective reversible ALDH-2 inhibitor, CVT-10216, in models of moderate and high alcohol drinking rats [261]. Results of this 
study showed that treatment with CVT-10216 reduces heavy drinking in rodents, suppresses alcohol self-administration, deprivationinduced drinking and cue-induced reinstatement of alcohol-seeking, an animal model of relapse. The authors suggested that CVT-10216 may prevent alcohol-induced increase in NAc DA.

A study by Xie and colleagues [262] showed that i.p. administration of daidzin reduces intoxication induced by anaesthetic doses of alcohol in rats. Notably, the effects of daidzin in shortening alcohol-induced sleep time, a reliable measure of alcohol intoxication, was found after intragastric, but not i.p. infusion of alcohol, suggesting that the effects of daidzin are also due to a slowdown of gastric emptying, which would expose alcohol for a longer time to first-pass metabolism [263]. Some effects in reducing alcohol withdrawal symptoms were also observed for daidzein and puerarin [259,260,264]. In particular, Overstreet and colleagues showed that the extract of kudzu NPI-031G (puerarin) was effective in counteracting anxiogenic effects associated with alcohol withdrawal in rats exposed chronically to alcohol, suggesting an underlying mechanism of antagonism at the benzodiazepine receptors [264].

In humans, a randomized double-blind controlled trial evaluated the efficacy of kudzu root extracts in influencing drinking habits of veterans who entered a substance abuse treatment program [265]. Alcohol dependent patients were randomly assigned to receive kudzu root extracts $1.2 \mathrm{~g}$ twice daily (21 patients) or a matching placebo (17 patients). In this small sample, kudzu root was no better than placebo in reducing alcohol craving, or in promoting abstinence [265]. A subsequent clinical trial was conducted to evaluate the efficacy of a kudzu extract in heavy drinkers treated with either a kudzu extract or placebo for 7 days [266]. Participants had then the opportunity to drink their preferred brand of beer while in a laboratory setting. Results of this study showed a significant reduction in the number of beers consumed in one week of treatment, as well as an increase in the number of sips, an increase in the time to consume each beer and a decrease in the volume of each sip. There were no changes in the urge to drink alcohol, suggesting that kudzu probably does not act blocking alcohol's effects but instead prolonging or enhancing the acute effects of the first drink [266].

\section{NICOTINIC AND MUSCARINIC ACETYLCHOLINE RE- CEPTORS (nAchRs AND mAchRs)}

The central cholinergic system has been implicated in the development of alcohol and drug addictions. The receptors of the cholinergic system are divided into muscarinic acetylcholine receptors (mAchRs) and nicotinic acetylcholine receptors (nAchRs). The potential role of nAchRs in the treatment of alcohol and drug addictions has been more extensively studied than that of mAchRs [267].

Mesocorticolimbic DA neurons are known to contain central nAchRs that modulate the accumbal release of DA [268]. Alcoholinduced stimulation of the mesolimbic DA system may involve central nAchRs, suggesting their possible involvement in the initiation phase of alcohol consumption [269]. Other experiments also demonstrated an involvement of these receptors in the mechanisms of maintenance of alcohol consumption and relapse to alcohol use [269]. Blomqvist and Ericson have extensively studied the involvement of nAchRs in the mechanisms of alcoholism and found that ethanol activates the mesocorticolimbic DA system via both direct and indirect stimulation of central nAchRs NAc [270,271]. Moreover, mecamylamine, a blood brain barrier penetrating nAchR antagonist, completely antagonizes both of these effects [272]. On the basis of these observations, the effects of two nAchR antagonists, mecamylamine and hexamethonium, as well as the effects of subchronic nicotine treatment on voluntary ethanol consumption were studied in ethanol low-, medium- or high-preferring Wistar rats [270]. Mecamylamine but not hexamethonium reduced ethanol intake in high-preferring rats, while subchronic nicotine treatment increased ethanol consumption in rats with a medium preference for alcohol. Neither mecamylamine nor hexamethonium reduced ethanol preference. On the basis of these results, the authors suggested that antagonists at nAchRs could be useful compounds in the treatment of alcoholic subjects [270]. A subsequent study by the same research group provided further evidence on the possible role of mecamylamine in the treatment of alcoholism [273] as ethanol intake and preference in Wistar rats were markedly reduced and DA levels were unaltered with respect to pre-drug baseline levels [273]. In a more recent study, Farook and colleagues [274] using alcoholpreferring $\mathrm{C} 57 \mathrm{BL} / 6 \mathrm{~J}$ mice reported that there was a reduced consumption of alcohol in daily and intermittent mecamylamine-treated (intermittent) mice than in control mice.

Twelve different $n A c h R$ subunits ( $\alpha 2-\alpha 10$ and $\beta 2-\beta 4)$ have been identified and these subunits can constitute a multitude of pentameric nAchRs with different molecular configurations. These $\mathrm{nAchRs}$ are expressed in varying patterns and densities throughout the brain, e.g. the mRNAs for the $\mathrm{nAchR}$ subunits $\alpha 3-\alpha 7$ and $\beta 2-\beta 3$ have been found highly expressed within the VTA [275]. Moreover, variations in the nAchR subunit composition may influence the sensitivity to ethanol. In order to examine the role of different nAchR subunits in operant ethanol self-administration and in ethanol drinking relapse following a 10-day period of ethanol deprivation, Kuzmin and colleagues [275] compared the nicotinic subunitspecific antagonist $\alpha$-conotoxin MII ( $\alpha$ CtxMII, $\alpha 3 \beta 2, \beta 3, \alpha 6)$ with systemic mecamylamine, dihydro- $\beta$-erythroidine (DH $\beta E, \alpha 4 \beta 2$ ) and methyllycaconitine (MLA, $\alpha 7$ ). $\alpha$ CtxMII was administered directly into VTA, whereas mecamylamine, DH $\beta E$ and MLA were administered systematically. Results of the study showed that $\alpha \mathrm{CtxMII}$ reduced operant ethanol self-administration and blocked the deprivation-induced relapse-like ethanol consumption; mecamylamine reduced operant ethanol self-administration and inhibited the deprivation-induced increase in alcohol consumption; DH $\beta \mathrm{E}$ inhibited ethanol intake only at a higher dose; MLA failed to block self-administration of ethanol and relapse-like drinking after deprivation. These results suggested that modulation of central effects of ethanol are mediated mainly by $\alpha 3 \beta 2$ and/or $\beta 3$ subunits of nAchRs. Therefore, ligands for these subunits might be of greater interest for alcohol pharmacotherapies [275].

Lobeline is a naturally occurring alkaloid obtained from the plant Lobelia inflate, that binds to nAchRs with high affinity, displaying both agonist and antagonist activity. In a recent study, the effects of repeated administration (continuous or recurring for 5 days) of the partial nicotinic agonist lobeline on alcohol consumption and alcohol preference were investigated in a high alcohol preferring strain of mice [276]. Lobeline attenuated alcohol consumption and preference during both the repeated-recurring and continuous administration phases, probably by activating both high $(\alpha 4 \beta 2)$ and low affinity $(\alpha 7)$ central nAchRs [276]. The effects of lobeline and of the $\mathrm{nAchR}$ partial agonist cytosine on ethanol drinking were then investigated by Bell and colleagues [276]. At high doses both nAchR ligands independently suppressed ethanol intake. Specifically, cytosine suppressed ethanol intake, by attenuating $\alpha 4 \beta 2 \mathrm{nAchR}$ function and lobeline suppressed ethanol intake, by acting as a nonselective competitive antagonist at $\alpha 4 \beta 2$ and $\alpha 3 \beta 2$ nAchRs. Practically, both cytosine and lobeline act as functional antagonists at nAchRs, which in turn lead to reduce alcohol induced DA release in the NAc and consequently, to attenuate the reinforcing properties of ethanol.

Varenicline, a cytosine derivate, is a partial agonist at the $\alpha 4 \beta 2$ nAchRs and has been approved for marketing in the U.S. and in more than 30 countries worldwide as an aid for smoking cessation [277]. Varenicline, at higher concentrations, can interact with other nAchRs subtypes, in addiction to $\alpha 4 \beta 2$, including the $\alpha 7$ homomeric receptor subtype. A role of $\alpha 7 \mathrm{nAChRs}$ in modulation of ethanol response has been hypothesized, although a recent study using mice with a constitutive knockout of either the $\alpha 7$ or $\beta 2$ subunit found that neither subunit is absolutely required for the 
effect of varenicline on ethanol intake [278]. Steensland and colleagues [279] investigated the role of varenicline in the modulation of alcohol consumption and alcohol seeking using three different animal models of drinking. Acute administration of varenicline, in doses reported to reduce nicotine reward, selectively reduced ethanol but not sucrose seeking and decreased voluntary ethanol consumption in animals chronically exposed to ethanol for two months before varenicline treatment. Moreover, chronic varenicline administration reduced ethanol consumption, which did not result in a rebound increase in ethanol intake when varenicline was discontinued. Furthermore, varenicline appears to ameliorate ethanol-induced cognitive deficits, in particular deficits in acquisition of contextual and cued associative learning [280].

Few studies investigating the efficacy of nAChRs ligands in the treatment of alcoholism have been conducted in humans. The first clinical study by Blomqvist and co-workers [281] investigated the effects of mecamylamine on subjective responses of healthy subjects to a moderate dose of alcohol. Results of the study showed that mecamylamine, as compared to placebo, reduced the stimulant and pleasurable effects of an acute administration of alcohol during the ascending limb of the blood alcohol curve, probably by modifying both the pharmacokinetic profile of alcohol and the rewarding effects. Chi and de Wit [282] replicated and extended this study using a double-blind design. As compared to placebo, mecamylamine reduced subjective euphoria after alcohol intake and desire to consume more alcohol. However, a more recent study with mecamylamine did not confirm these observations [283]. To date only one human study using varenicline for alcoholism has been published [284]. This study was a double-blind, placebo-controlled trial in which the effect of varenicline ( $2 \mathrm{mg}$ /day vs. placebo) on alcohol self-administration was investigated in 20 non alcohol-dependent heavy drinkers who were also daily smokers. After seven days of medication pre-treatment, subjects were first administered a priming dose of alcohol $(3 \mathrm{~g} / \mathrm{kg})$ and subjective and physiologic responses were assessed. The participants were exposed to a 2-hour drinking period during which they were permitted to drink up to eight alcoholic drinks or to receive monetary reinforcement for each drink not consumed. Results showed that varenicline significantly reduced the number of drinks consumed compared to placebo and increased the likelihood of abstaining from any drinking during the self-administration period. Furthermore, following the priming drink, varenicline attenuated alcohol craving and reduced subjective reinforcing alcohol effects, without significant side effects.

These promising results have aroused interest in respect of varenicline as a new medication target for alcohol use disorders. In fact, there are several ongoing clinical and human laboratory trials designed to investigate both the effects of varenicline on heavy drinking and the effectiveness in the treatment of $\mathrm{AD}$ (e.g. NCT00846859, NCT01071187, NCT00695500).

Muscarinic acetylcholine receptors (mAchRs) are predominantly presynaptic autoreceptors, being responsible for acetylcholine-mediated inhibition of adenyl cyclase activity. mAchRs primarily provide negative feedback on acetylcholine release from cholinergic terminals [285] and are involved in many brain function, including attention, learning, memory and cognition [286]. Several studies showed an association between the muscarinic acetylcholine M2 receptor (CHRM2) gene and AD [286,287]. In particular, one haplotype block within the 5'-UTR of CHRM2 may be more important for the development of alcoholism than other regions [287]. Thus, an involvement of mAchRs in the neurobiological mechanisms of alcoholism could be hypothesized. However, at present there are no human or animal studies that have investigated $\mathrm{mAchRs}$ as a new potential target for the treatment of AD.

\section{ACETYLCHOLINESTERASE INHIBITORS}

A possible role of acetylcholinesterase inhibitors for alcoholism has been hypothesized. In fact, cholinesterase inhibitors act on the breakdown of the neurotransmitter acetylcholine and prolong acetylcholine retention time in the synaptic cleft and therefore, the efficiency of cholinergic neurotransmission at both mAChRs and nAChRs [288]. Galantamine, an alkaloid of many plants of the Amaryllidaceae family and of various species of narcissus, is a reversible acetylcholinesterase inhibitor which also acts as an allosteric potentiating ligand at neuronal nAChRs, especially at the $\alpha 7$ and $\alpha 4 \beta 2$ nAChRs, but not at mAChRs [289]. Opitz [290] first described a role of galantamine in reducing ethanol preference in an animal model of AD. After oral administration of galantamine at doses of 5 or $10 \mathrm{mg} / \mathrm{kg}$, in the following 1-2 h exposition time both alcohol preference and ethanol intake were reduced significantly. Galantamine reduced alcohol intake without decreasing food consumption and total fluid intake. Subsequently, galantamine has also shown to improve the speed of learning, short-term memory and spatial orientation in rats after prolonged (16 weeks) alcohol intake [291]. This last observation is consistent with the hypothesis that prolonged alcohol intake could lead to an acetylcholine deficit and to an impairment of many brain functions.

More recently, the effects of galantamine on voluntary ethanol consumption were investigated in female Alko alcohol rats, in combination with desoxypeganine, an alkaloid derived from Peganum harmala. In this experiment, desoxypeganine, initially administered reduced ethanol intake and ethanol preference and these effects were dose-dependent, at a dose ranged between 10 and $30 \mathrm{mg} / \mathrm{kg}$ body weight. In this preclinical study, the combination of desoxypeganine and galantamine in doses which were ineffective when administered alone, caused a significant decrease of ethanol preference in rats, suggesting an addictive effect [292].

Based on the preclinical studies, Mann and colleagues [293] investigated the efficacy of galantamine in prolonging abstinence in recently detoxified alcoholics. A 24-week, randomized, placebocontrolled, multicenter clinical trial involving 149 recently detoxified alcohol dependent patients was conducted. Galantamine at the dose of $25 \mathrm{mg} / \mathrm{d}$ or placebo were administered by a patch that was renewed every morning during the first 12 weeks (treatment phase), then no patch was applied during the successive 12-week period (follow-up phase). Patients also received a low-intensity psychosocial standard therapy at each visit. Results of the study showed that galantamine, compared to placebo, did not extend the time to first severe relapse. Moreover, at the end of the 12-week treatment period, significantly fewer patients assigned to galantamine remained abstinent $(20 \%)$ compared to placebo group $(41 \%)$. The same results were observed at the end of the follow-up period (week 24). The contradictory findings, between preclinical and clinical observations, could be explained by the different way galantamine was administered. Compared with oral administration, the patch offers a very different pharmacokinetic profile and probably, the applied dose of $25 \mathrm{mg} / \mathrm{d}$ was not sufficient to achieve effective plasma levels of the drug. In fact, the average plasma concentration of galantamine was $7.1 \pm 9.1 \mathrm{ng} / \mathrm{ml}$, lower than the expected $16.7 \pm 9.35$ $\mathrm{ng} / \mathrm{ml}$ [293]. Another explanation, provided by the authors, is related to the rapid eye movement (REM). REM pressure during sleep is dependent on the central cholinergic system and rises with increased cholinergic activity [294]. In turn, the increased REM sleep induced by galantamine in alcohol dependent patients after alcohol withdrawal represents a robust predictor of vulnerability to relapse [294]. Therefore, it might be possible that an increased REM induced by galantamine induced the recently detoxified alcoholics to relapse [293]. Nevertheless, further studies are needed to explore if galantamine represents a potential treatment for AD. 


\section{GLYCINE REUPTAKE INHIBITORS}

Ethanol administration is known to increase DA output in the NAc of the rats [295] as well as in humans [2], and this increase has been hypothesized to be of importance for the development of AD [296]. The mechanisms by which DA participates in alcoholseeking behaviour and how the mesolimbic DA activity is regulated have been extensively investigated. Recently, glycine and strychnine-sensitive glycine receptors (GlyRs) generated interest in the field of $\mathrm{AD}$, considering their involvement in the $\mathrm{DA}$ activity.

Glycine is the major inhibitory neurotransmitter in the spinal cord and brain stem and it has been implicated in controlling neuronal excitability and psychotic symptoms [297]. Glycine receptors have also been identified in the CNS and they are expressed on both dopaminergic and non-dopaminergic cells of the VTA [298]. Glycine activates GlyRs and determines a reduction of inhibitory GABAergic inputs to VTA dopaminergic neurons, producing an increase in accumbal DA release [298]. In vitro studies showed that ethanol potentiates glycine receptor function [299,300]. Successively, Molander and Soderpalm [301,302] demonstrated that GlyRs are expressed in the rat NAc and that activation of these receptors might constitute a priming mechanism for ethanolinduced enhancement of accumbal DA activity. In particular, a local perfusion of strychnine, a GlyR antagonist, decreases accumbal DA levels per se and completely prevents the increase of accumbal DA levels after both local and systemic ethanol administration. Instead, accumbal perfusion of the GlyR agonist glycine increases DA levels in a subpopulation of rats and prevents the ethanol-induced increase after local but not systemic ethanol in all animals [302]. The same authors also investigated the role of accumbal GlyRs in the regulation of voluntary ethanol intake in the rats and found that glycine and strychnine altered extracellular DA levels in the NAc, probably via GlyR stimulation and blockade, respectively [303]. Concomitantly, strychnine and glycine reciprocally altered ethanol consumption in ethanol high-preferring rats, respectively decreasing and increasing ethanol intake [303]. Thus, results of these experiments suggest that GlyRs agonists and/or antagonists could represent interesting new ways to treat alcohol dependence.

Other research has focused on the possible role of glycine transporter (GlyT) inhibitors in voluntary alcohol consumption. GlyT proteins are involved in the reuptake of glycine into presynaptic nerve terminals and glial processes, allowing the return of extracellular levels of glycine to basal values. There are two known types of GlyT proteins, the GlyT1 and the GlyT2 located on glia cells and glycinergic neurons, respectively. The GlyT1 catalyses the removal of glycine from the synaptic cleft and the GlyT2 is involved in the reuptake and reloading of glycine into synaptic vesicles [304]. Molander and colleagues [304] investigated the role of a selective glycine reuptake inhibitor (Org 25935) in decreasing alcohol intake and preference in rats. Org 25935 easily passes the blood-brain barrier and acts mainly on the GlyT1 protein. Ge et al. [305] administered Org 25935 via i.p. to male Wistar rats with an ethanol preference $>60 \%$ (during continuous access to a bottle of alcohol, $6 \% \mathrm{v} / \mathrm{v}$, and a bottle of water) and to rats with an ethanol preference $<60 \%$. Org 25935 was effective in reducing alcohol intake in both populations of rats. This effect was dose-dependent, developed gradually and was sustained for up to 40 days. Food intake was also transiently reduced. The mechanism underlying the effects of Org 25935 in reducing alcohol intake is probably represented by an increase of extracellular glycine levels and a subsequent modulatory effect on brain GlyRs. A more recent study investigated the DA output in the NAc after systemic administration of Org 25935 and ethanol [306], that suggests the involvement of the glycine/GlyR system in modulating basal accumbal DA levels and in the ethanol-induced elevations of DA in the NAc. Based on these studies, it was supposed that the anti-alcohol effect of Org 25935 is due to i) a substitution mechanism by stimulation of GlyRs and elevation of DA levels; and ii) antagonism mechanism by prevention of further GlyR activation and DA elevation by ethanol.

Based on this first preclinical evidence, a double-blind, placebo-controlled clinical trial is currently investigating the safety, tolerability and efficacy of Org 25935 on alcohol-dependent individuals (NCT00764660).

\section{ALPHA-ADRENERGIC RECEPTOR}

Norepinephrine in the limbic system is important to emotional learning and may be involved in the neuroadaptations that lead to the development of dependence. In the amygdala, increased norepinephrine (NE) activity leads to creation of stronger and longer-lasting memories [307]. NE depletion produced by blockade of the synthetic pathway attenuates ethanol-self administration in rats [308]. Ligands targeting different receptor subtypes of the NE system have been most extensively studied for reducing certain aspects of ethanol withdrawal symptomology. In particular, it has been shown that $\beta$-adrenergic antagonists and $\alpha 2$-noradrenergic receptor agonists appear to be efficacious in reducing withdrawal symptoms and $\alpha 1$-noradrenergic receptor antagonists in reducing locomotor hyperactivity produced by ethanol withdrawal [309].

Though early work suggested that the NE reuptake inhibitor desipramine prolonged the time to relapse in depressed alcoholics [310,311], research on alcohol pharmacotherapy has been slow to focus on the NE system. Recently, this interest has been renewed. Initially, research focused on the $\alpha 2$-adrenoceptor antagonist yohimbine, while more recent research is focusing on the prototype $\alpha_{1}$-blocker prazosin.

Yohimbine, an $\alpha 2$-adrenoceptor antagonist which acts by increasing norepinephrine cell firing and norepinephrine release in terminal areas, was proposed as an effective drug in the treatment of $\mathrm{AD}$ [312]. In this study, injections of the $\alpha 2$-adrenergic receptor antagonists, yohimbine and methoxyidazoxan, to rats decreased intake of alcoholic beverage and increased intake of water. Furthermore, yohimbine alone persistently reduced intake of alcohol with daily administration [312]. However, subsequent studies did not confirm these observations. Indeed, it was shown an effect of yohimbine in reinstating alcohol seeking both in rats and in humans probably by inducing anxiety- and stress-like response and acting as a pharmacological stressor [313].

Prazosin, an $\alpha 1$-noradrenergic receptor antagonist, has aroused interest as effective drug in reducing alcohol intake. Prazosin was evaluated for the ability to modulate operant ethanol selfadministration in non-dependent and ethanol-dependent animals during acute withdrawal [309]. In this study, prazosin at different dosages $(0.0,0.25,1,1.5$ and $2 \mathrm{mg} / \mathrm{kg})$ was administered to ethanol dependent and control rats during acute withdrawal. Prazosin reduced self-administration of ethanol in both non-dependent and ethanol-dependent rats during acute withdrawal. However, prazosin was more potent in ethanol-dependent animals, suggesting an increase in the sensitivity to prazosin in dependent animals due to alterations in the norepinephrine system during chronic exposure to ethanol. Then, Rasmussen and colleagues [314] tested the efficacy of prazosin in suppressing alcohol drinking in rats selectively bred for alcohol preference ( $\mathrm{P}$ line). Adult male $\mathrm{P}$ rats were given open access to food and water and scheduled access to a $15 \%(\mathrm{v} / \mathrm{v})$ alcohol solution for 2 hours daily. Prazosin at different doses $(0,0.5$, $1.0,1.5$, or $2.0 \mathrm{mg} / \mathrm{kg}$ body weight) was injected i.p., once a day prior to onset of the daily 2-bottle choice (alcohol vs. water), for 3 weeks. Prazosin significantly reduced alcohol intake during the initial 2 daily administrations, and this reduction of alcohol intake was maintained in the subsequent more prolonged trial and was not dependent upon drug-induced motor impairment

Based on these promising preclinical results, Simpson and colleagues [315] tested the effectiveness of prazosin in reducing drinking and craving for alcohol among AD patients. Twenty-four alco- 
hol-dependent patients were randomized to receive either prazosin or placebo in a 6-week, double-blind pilot study. Medication was titrated to a target dose of $4 \mathrm{mg}$ QAM, $4 \mathrm{mg}$ QPM, and $8 \mathrm{mg}$ QHS by the end of week 2. Results of the study showed fewer drinking days and drinks per week in the prazosin group with respect the placebo group during the final 3 weeks of the study. With regard to craving, although the entire sample on average reported significantly decreased craving from baseline to the final assessment, the prazosin group did not report significantly less craving than the placebo group. No significant side-effects were reported, although one of the prazosin-treated participants experienced syncope, requiring a dose reduction. At present, large controlled studies are in progress to further investigate the role of prazosin in $\mathrm{AD}$ (e.g. NCT00762710).

\section{CALCIUM-ACTIVATED-POTASSIUM (CAK) CHANNELS}

In CNS neurons, calcium-activated-potassium (CAK) channels modulate neuronal activity by controlling intrinsic excitability, tonic firing frequency, spike frequency adaptations, and action potential repolarization. These channels are activated by elevations in intracellular $\mathrm{Ca} 2+$ that occurs during single or trains of action potentials, and their activation is thought to contribute to the prolonged after hyperpolarization that follows an action potential.

CAK channels are defined by two phenotypic characteristics: their pores conduct $\mathrm{K}+$ rather selectively over other monovalent ions, and their steady-state activity is enhanced by increases in intracellular calcium. Based on their $\mathrm{K}+$ permeability, three types of CAK channels have been recognized and they demonstrate heterogeneous pharmacological and kinetic properties: small (SK), intermediate (IK) and large conductance (BK or MaxiK) [316,317]. SK and BK have been more extensively studied in alcohol dependence.

SK channels underlie the medium phase of the hyperpolarization and are important for shaping postsynaptic responses and controlling intrinsic excitability, dendritic integration, and pacemaker firing.

The spontaneous action potential of VTA neurons is determined by a number of voltage and $\mathrm{Ca} 2+$-dependent currents, which involve SK channels [318]. Since ethanol directly excites DA VTA neurons [319], a recent study addressed the possibility that repeated ethanol exposure and withdrawal leads to altered firing properties of VTA DA neurons through changes in SK channel function [320]. Specifically, Hopf and colleagues [320] used ex vivo brain slice electrophysiology to characterize whether pacemaker firing and NMDA-induced burst firing in VTA neurons were altered after 5 days of intermittent ethanol exposure and 7 days of withdrawal, and what channels might be altered functionally to explain any observed firing differences. This study demonstrated that repeated ethanol and withdrawal leads to a significant reduction in VTA SK currents [320]. Thus, SK channels are a critical component of the VTA neuronal membrane conductance and play an important role in DA VTA neurons, i.e. altering the responsiveness of these neurons to external stimulation, either by endogenous agents, like neurotransmitters, or by exogenous agents, like alcohol.

Other studies showed that the excitatory effects of ethanol can be modulated by a number of agents that block SK channels or affect $\mathrm{Ca} 2+$ levels and release [318]. Moreover, manipulation of $\mathrm{Ca} 2+\mathrm{i}$ levels and release can result in reduction of overall $\mathrm{Ca} 2+\mathrm{i}$, and, as a direct antagonism of SK, these manipulations can increase the excitatory action of ethanol [321]. Finally, a recent study has shown an association between reduced small-conductance calciumactivated potassium channel (SK) currents and increased firing in the NAc core after protracted abstinence from alcohol but not sucrose self-administration [322]. In conclusion, consistent with evidence of an interaction between ethanol and SK currents in reward neurons of the VTA, SK channels may represent a novel target to treat $\mathrm{AD}$.
The BK channels are largely expressed in the brain and contribute to the fast phase of the AHP. These channels play an essential role in many aspects of neuronal physiology, including neurotransmitter release, action potential patterning and dendritic excitability. In addition, a number of studies have also implicated an important role for BK channels in ethanol tolerance and adaptive plasticity [317-323].

The BK channel is composed of a primary protein, containing a pore that acts as a conduit for $\mathrm{K}+$ ions. This primary protein is often combined with a variety of auxiliary proteins (b1-b4) that modify the function of the channel, including alcohol sensitivity. Compartment-specific expression of $b$ subunits of the BK channels has been proposed to explain differences in BK-related alcohol sensitivity between the somatic, dendritic and terminal compartments of neurons [324]. One of these auxiliary proteins, known as b4, plays a key role in acute alcohol tolerance. In fact, an experiment with mice knocked out for the gene encoding the b4 subunit [325] showed that the b4 subunit inhibits acute alcohol tolerance and the presence of acute tolerance is an indicator of alcohol consumption.

There is also evidence that lipid composition of biological membranes is altered differently by acute and chronic alcohol exposure as experiments with BK channels provide evidence of the powerful effects that lipid environment can have in both the immediate and adaptive response to alcohol, considering that $\mathrm{BK}$ might move into and out of lipid rafts, thereby changing both the acute response and adaptation to alcohol [326,327].

\section{VOLTAGE-GATED CALCIUM CHANNELS}

Voltage-gated calcium channels (VGCCs) are multimeric protein complexes that mediate $\mathrm{Ca} 2+$ entry into neurons in response to changes in membrane potential and regulate neuronal excitability, neurotransmitter release, and gene expression. They are classified according to their electrophysiological and pharmacological properties [328]. High voltage-activated N-type calcium channels are exclusively expressed in the nervous system, where they contribute to neurotransmitter release at a subset of central and peripheral nerve terminals [329]. Low voltage-activated T-type calcium channels are biophysically distinct from $\mathrm{N}$-type channels and contribute to rhythmic firing and bursting behaviours related to processes such as sleep and epileptiform activity [330].

Acute ethanol exposure inhibits $\mathrm{N}$-type calcium channels, and chronic ethanol exposure increases $\mathrm{N}$-type channel function and density. Ethanol appears to have complex effects on T-type currents. In slices from the lateral geniculate nucleus, low concentrations of ethanol potentiate T-type currents, whereas higher ethanol concentrations inhibit T-type currents [331]. The principal defined role for N-type calcium channels is the regulation of evoked neurotransmitter release [332].

Newton et al. [333] chose a genetic approach by studying ethanol responses in mice that carry a null mutation in the calcium channel subunit Cav2.2 and therefore lack functional N-type calcium channels. In these animals, voluntary ethanol consumption is reduced and place preference is developed only at a low dose of ethanol. The hypnotic effects of ethanol are also substantially diminuished, whereas ethanol-induced ataxia is mildly increased. These results demonstrate that $\mathrm{N}$-type calcium channels modulate acute responses to ethanol and are important mediators of ethanol reward and preference [333].

The same group tested the effect of a novel mixed inhibitor of $\mathrm{N}$-type and T-type calcium channels, 1-(6,6-bis(4-fluorophenyl) hexyl)-4-(3,4,5- trimethoxybenzyl) piperazine (NP078585) in animal model of ethanol intoxication, reinforcement, reward, and reinstatement. The results of these studies showed that NP078585 reduced the acute effects of ethanol and abolished the expression of ethanol conditioned place preference in mice [334] supporting the 
hypothesis that $\mathrm{N}$-type calcium channels contribute to ethanol intoxication, reinforcement, reward, and reinstatement.

Considering that $\mathrm{N}$-type calcium channel inhibitors are being developed for clinical use, these data show the possibility that AD individuals treated with $\mathrm{N}$-type or mixed $\mathrm{N}$ - and $\mathrm{T}$-type calcium channel inhibitors may become less motivated to experience the effects of ethanol.

\section{SIGMA-RECEPTORS (SigRs)}

Sigma receptors (SigRs) were originally called as sigma/opioid receptors because the effect of the prototypic sigma/opioid receptor ligand, $\mathrm{N}$-allylnormetazocine, was reported to be antagonized by the opioid antagonist naloxone [335]. At least two subtypes of sigma receptors, SigR1 and SigR2, are known.

Because SigR1s are involved in regulating dopaminergic, NMDA and glutamatergic neurotransmission in limbic areas, including the NAc and the VTA a role of SigR1 in development of $\mathrm{AD}$ has been hypothesized. Miyatake and colleagues [336] performed a functional analysis of polymorphisms in the SigR1 and a case-control study, involving 307 alcoholic and 302 control subjects. These investigators not only identified the novel T-485A polymorphism, but also found that the transcriptional activity of the A-485 allele and the TT-241-240 allele was significantly reduced compared with that of the T-485 allele and the GC-241-240 allele. Moreover, the frequencies of the A-485 allele and the TT-241240/Pro2 haplotype were significantly higher in control subjects compared with alcoholic subjects, suggesting a possible protective role for the development of alcoholism [336].

More recently, a role of SigR antagonists in modulating ethanol's actions has been proposed. A recent study investigated the effects of subcutaneous treatment with the potent, selective SigR1 antagonist BD-1063 on operant ethanol self-administration in two models of excessive drinking (Sardinian alcohol-preferring (sP) rats and ethanol-dependent Wistar rats), compared to non-dependent Wistar controls [337]. BD-1063 dose-dependently and selectively reduced oral ethanol self-administration in $\mathrm{sP}$ rats and in ethanol dependent Wistar rat. Moreover, BD-1063 reduced the motivation of sP rats to work to obtain alcohol. A significant decrease of SigR1 mRNA expression in the NAc was found in both ethanol-naïve sP rats and ethanol-dependent Wistar rats with respect to ethanol-naïve control Wistar rats, suggesting a role of SigR1s in the modulation of excessive ethanol intake and reinforcement and a role of SigR1s antagonists as potential target for medication development for treatment of alcoholism [337]. Further confirming preclinical studies and exploratory human studies are needed to confirm this initial evidence.

\section{MELANOCYTE STIMULATING HORMONE (MSH)}

A role for melanocortins (MC) peptides in neurobiological responses to drugs of abuse has been established. The MC system is composed of peptides that are cleaved from the polypeptide precursor, proopiomelanocortin (POMC), which is also the precursor for $\beta$-endorphin. These peptides include adrenocorticotropic hormone (ACTH), $\alpha$-melanocyte stimulating hormone ( $\alpha-\mathrm{MSH}), \beta-\mathrm{MSH}$, and $\gamma$-MSH [338]. The production of these peptides occurs in the neurons within the hypothalamic arcuate nucleus, the nucleus of the solitary tract, and the medulla. At least five subtypes of MC peptides receptors, including MC4R, have been identified [338], which have been implicated in most behavioural effects including neurobiology of depression [339].

An involvement of MC signalling in $\mathrm{AD}$ has been suggested. In order to investigate the involvement of the MCs in $\mathrm{AD}$, Ploj and colleagues [340] analysed the effects of the MC4R antagonist HS014 (1 nmol/rat), and the non-selective MC-receptor agonist MTII (1 nmol/rat), administered i.c.v., on ethanol intake in alcoholpreferring AA rats. MTII caused a reduction in ethanol intake and ethanol preference, whereas HS014 had no any effect. Simultane- ously, MTII and HS014 altered opioid peptide levels in several brain areas and in the pituitary gland of alcohol-preferring AA rats the rats.

Navarro and colleagues [341] extended the previous findings [340] by showing that both central and peripheral administration of MTII reduces ethanol drinking. Subsequently, the same group demonstrated that an i.c.v. infusion of the highly selective MC4R agonist cyclo (NH-CH2-CH2-CO-His-d-Phe-Arg-Trp-Glu)-NH2 at doses of 1.0 or 3.0 microg significantly reduced ethanol drinking in rats [342]. In a more recent study, the role of $\alpha-\mathrm{MSH}$ in mediating the acute and chronic effects of ethanol and withdrawal-related depression was investigated in rats [338]. Results of the study showed that $\alpha-\mathrm{MSH}$ may be closely involved in mediating the actions of ethanol and that the nature of interaction may be dictated by the protocol of ethanol treatment. Central administration of $\alpha$ MSH (100 ng/rat, i.c.v.) was found to suppress the anti-immobility effect of acute ethanol, while HS014 (0.01 ng/rat, i.c.v.) was found to enhance. Chronic ethanol exposure resulted in increased immobility time, while further augmentation in immobility was noticed following ethanol withdrawal. However, concomitant HS014 (0.01 $\mathrm{ng} / \mathrm{rat}$, icv) treatment prevented tolerance as well as attenuated enhanced immobility in ethanol-withdrawn rats. In brief, while acutely administered ethanol causes antidepressant-like effect and may trigger antagonistic homeostatic response from the $\alpha$-MSH, chronic ethanol treatment results in the up-regulation of the entire $\alpha-\mathrm{MSH}$ system that may contribute to the tolerance.

The present data support the hypothesis that the endogenous MC system modulates neurobiologic responses to ethanol. Thus, compounds that target MCRs may a have therapeutic value in the treatment of excessive ethanol consumption and/or the symptoms associated with ethanol withdrawal.

\section{VASOPRESSIN}

A growing body of evidence suggests that vasopressinergic neuronal activity in the amygdala and PVN of the hypothalamus represents an important element in the neurobiology of stressrelated behaviours. In fact, acute stress increases extracellular levels of arginine vasopressin (AVP) in the rat amygdala and hypothalamus [343,344], and activation of AVP-receptors modulates anxiogenic and depressive behaviours in rats [344]. Vasopressin binds to three different $\mathrm{G}$ protein-coupled receptor subtypes: V1a, V1b, and V2. The V2 receptor is expressed almost exclusively in the kidney. The V1a and V1b receptors are localized in the brain, and the distribution of vasopressin receptor binding is prominent in the rat extended amygdala, with high concentrations in the lateral and supracapsular bed nucleus of the stria terminalis, the central nucleus of the amygdala, and the shell of the NAc [345].

Prolonged or chronic ethanol exposure decreases vasopressinlike immunoreactivity in the hypothalamus and the bed nucleus of the stria terminalis projection to the lateral septum [346]. A selective $\mathrm{V} 1 \mathrm{~b}$ receptor antagonist dose-dependently blocks the increase in ethanol self-administration during withdrawal in dependent rats but has no effect in nondependent animals [347]. To date, few studies have explored the motivational effects of vasopressin antagonists in animal models of dependence or stress-induced reinstatement with other drugs of abuse. However, the literature suggesting that V1b antagonists have anxiolytic like profiles and that vasopressin and its receptors are highly expressed in the extended amygdala lead to hypothesize that the vasopressin system may have a role in the increased alcohol intake associated with dependence [347].

\section{LUTEINIZING HORMONE (LH)}

Hypothalamic luteinizing hormone releasing hormone (LHRH) neurons are projected to some of the brain regions implicated in the regulation of behaviour including the NAc and VTA. This may explain why LHRH analogues may exhibit a variety of effects such 
as antidepressant, anti-anxiety, analgesic, anticonvulsant, catalepsy, drug discrimination learning, and inhibition of condition avoidance response [348]. LHRH also modulates the activity of serotonin, glutamate, DA and opioids. A recent study showed that the LHRH agonist leuprolide exhibits an anticompulsive-like effect, and also mediates the anticompulsive effect of fluoxetine [349]. In view of the evidence that ethanol administration to rats reduces hypothalamic content of LHRH, suppresses LHRH secretion, reduces LHRH mRNA levels and inhibits LHRH binding to its receptor, it was speculated that ethanol dependence and withdrawal syndrome may be related to changes in the LHRH system [348]. In this connection, the effects of the LHRH agonist leuprolide on ethanol dependence were investigated in animals [348]. Since leuprolide modulates sex hormones levels, which are reported to influence behaviour, the studies were also carried out in castrated state.

The results of this study suggested that acute administration of leuprolide attenuated the expression of ethanol withdrawal behaviour, whereas on chronic administration, it attenuated the development of $\mathrm{AD}$, representing a potential new target.

\section{STEROID BIOSYNTHESIS}

Peripheral neuroactive steroids can act in the CNS as allosteric modulators of neurotransmitter receptors, such as GABA, NMDA, and sigma receptors. For instance, the progesterone metabolites allopregnanolone (ALLO), Tetrahydrodeoxycorticosterone (THDOC), and pregnanolone act as potent positive allosteric modulators at the GABA-A receptor [350]. Endogenous steroids have anxiolytic, anticonvulsant, analgesic and hypnotic properties, and also attenuate stress responses mediated by the HPA axis [351].

Some studies have shown that ethanol intake produces an elevation in both brain ALLO concentrations [352] and in plasma ALLO levels [353], in animals and humans, respectively. Furthermore, exogenous ALLO application stimulated limited-access ethanol drinking in male mice [354]. Moreover, administration of the 5alfa-reductase inhibitor finasteride (FIN), which decreases endogenous levels of ALLO, significantly altered ethanol drinking. In particular, subchronic FIN treatment (7 days) significantly attenuated limited access ethanol preference drinking in male C57BL $6 \mathrm{~J}$ mice [355]. Similar modifications were also observed in humans, where acute administration of FIN induces changes in both subjective states and neuroactive steroid concentration [356]. The observed correlations between the subjective and endocrine measures provide preliminary support for a role of these endogenous steroids in some of the subjective effects of alcohol.

In a recent work Ford et al. [357] hypothesized that inhibition of 5a-reduced neurosteroid biosynthesis would hinder the acquisition of ethanol intake, presumably by attenuating positive modulatory tone at GABA-A receptors. Thus, these investigators examined the effect of subchronic FIN administration on the acquisition of limited access ethanol preference drinking in male B6 mice. They found that FIN dose-dependently blocked the acquisition of drinking and prevented the development of ethanol preference, thereby suggesting that the GABAergic neurosteroids may be important in the establishment of stable drinking patterns. FIN-treated mice continued to exhibit attenuated ethanol consumption after 2 weeks post-treatment, despite a full recovery in brain ALLO levels. This study suggests that FIN-mediated modulation of the GABAergic system may be useful in curbing ethanol intake acquisition [357].

\section{IS THERE A PLACE FOR NON-PHARMACOLOGICAL NEUROBIOLOGICAL APPROACHES?}

Although beyond the goals of this review, we want to mention the recent and growing interest for some techniques, such as the transcranial magnetic stimulation (TMS). In fact, "boosting" the DA system should ameliorate compulsive drug/alcohol use [358], and this is the principle how TMS might work alcohol consumption. Transcranial magnetic stimulation is the first non-invasive non-pharmacological therapeutic approach to mental/brain disorders [359]. As such TMS promises to be an innovative approach to alcohol and other addictions with a negligible range of systemic side-effects and limited contraindications. In particular, recent technological developments such as the H-coil [360] allow modulation of brain regions as deep as $6 \mathrm{~cm}$ below cortical surface [360] thereby making the NAc accessible to external modulation.

\section{CONCLUSIONS}

This review has presented and discussed a variety of studies that have investigated possible new targets in the treatment of AD. These studies demonstrate a growing scientific excitement and complexity aimed at finding new pharmacotherapies for AD. Alcohol dependence is now considered a medical disease, but unlike other medical problems (hypertension, diabetes, just to cite few), only a few medications are available. Thus, there is a crucial need to develop new more effective pharmacotherapies for the treatment of $\mathrm{AD}$ patients. Future research will aim to translate the present data into clinical settings. However, translating preclinical into clinical success has its own challenges as we note that in some instances there is discordance between animal and human studies. Additionally there is a need to identify specific typologies of alcoholics who may benefit from specific pharmacotherapies [361]. In summary, future research must seek to identify not only efficacious medications, but also - and more importantly - to delineate the best match between a particular pharmacotherapy and a specific alcoholic typology.

\begin{tabular}{|c|c|c|}
\hline \multicolumn{3}{|c|}{ ABBREVIATIONS } \\
\hline$\alpha \mathrm{CtxMII}$ & $=$ & $\alpha$-conotoxin MII \\
\hline 18-MC & $=$ & 18-Methoxycoronaridine \\
\hline $\mathrm{ACD}$ & $=$ & Acetaldehyde \\
\hline Ach & $=$ & Nicotinic acetylcholine \\
\hline ACTH & $=$ & Adrenocorticotropic hormone \\
\hline $\mathrm{AD}$ & $=$ & Alcohol dependence \\
\hline $\mathrm{ADH}$ & $=$ & Alcohol dehydrogenase \\
\hline ALDH-2 & $=$ & Aldehyde dehydrogenase 2 \\
\hline ALLO & $=$ & Allopregnanolone \\
\hline AMPA & $=$ & Methylisoxazole-4-propionic acid \\
\hline ARC & $=$ & Arcuate nucleus \\
\hline AVP & $=$ & Arginine vasopressin \\
\hline BK or MaxiK & $=$ & Large conductance \\
\hline $\mathrm{Ca}^{+2}$ & $=$ & Calcium \\
\hline CAK & $=$ & Calcium-activated-potassium \\
\hline $\mathrm{CB}$ & $=$ & Cannabinoid \\
\hline $\mathrm{CeA}$ & $=$ & Central nucleus of amygdala \\
\hline $\mathrm{CFH}$ & $=$ & Corticotropin-releasing hormone \\
\hline CHRM2 & $=$ & Muscarinic acetylcholine M2 receptor \\
\hline $\mathrm{CNS}$ & $=$ & Central nervous system \\
\hline COGA & $=$ & $\begin{array}{l}\text { Collaborative Study on the Genetics of } \\
\text { Alcoholism }\end{array}$ \\
\hline CPP & $=$ & Conditioned place preference \\
\hline $\mathrm{CRF}$ & $=$ & Corticotropin-releasing factor \\
\hline CRFR & $=$ & Corticotropin-releasing factor receptor \\
\hline CYP2E1 & $=$ & Cytochrome P4502E1 \\
\hline DA & $=$ & Dopamine \\
\hline $\mathrm{DH} \beta \mathrm{E}$ & $=$ & Dihydro- $\beta$-erythroidine \\
\hline DR & $=$ & Dorsal raphe \\
\hline FDA & $=$ & Food and Drug Administration \\
\hline
\end{tabular}




\begin{tabular}{|c|c|c|c|c|c|}
\hline FIN & $=$ & Finasteride & pIIIu & $=$ & Perioculomotor urocortin \\
\hline GABA & $=$ & $\gamma$-aminobutyric acid & POMC & $=$ & Proopiomelanocortin \\
\hline GalR & $=$ & Galanin receptor & PTSD & $=$ & Posttraumatic Stress Disorder \\
\hline GDNF & $=$ & Glial cell line-derived neurotrophic factor & PVN & $=$ & Paraventricular nucleus \\
\hline $\mathrm{GH}$ & $=$ & Growth hormone & REM & $=$ & Rapid eye movement \\
\hline GHS-R & $=$ & Growth hormone secretagogue receptor & Ret & $=$ & Transfection receptor \\
\hline GlyR & $=$ & Glycine receptor & SigR & $=$ & Sigma-receptor \\
\hline GlyT & $=$ & Glycine transporter & SK & $=$ & Small conductance \\
\hline HPA & $=$ & Hypothalamic-pituitary axis & $\mathrm{SNc}$ & $=$ & Substantia nigra pars compacta \\
\hline i.c.v. & $=$ & Intracerebroventricular & $\mathrm{SP}$ & $=$ & Substance P \\
\hline i.p. & $=$ & Intraperitoneally & STAI & $=$ & Spielberg Trait Anxiety Inventory Test \\
\hline iGluR & $=$ & Ionotropic glutamate receptor & $\mathrm{TH}$ & $=$ & Tyrosine hydroxylase \\
\hline IK & $=$ & Intermediate conductance & THDOC & $=$ & Tetrahydrodeoxycorticosterone \\
\hline ITF & $=$ & Inducible transcription factor & TMS & $=$ & Transcranial magnetic stimulation \\
\hline $\mathrm{K}^{+}$ & $=$ & Potassium & Ucn & $=$ & Urocortin \\
\hline KA & $=$ & Kainic acid & US & $=$ & United States \\
\hline $\mathrm{LaH}$ & $=$ & Lateral hypothalamus & VGCC & $=$ & Voltage-gated calcium channels \\
\hline $\mathrm{LC}$ & $=$ & Locus coeruleus & VTA & $=$ & Ventral tegmental area \\
\hline
\end{tabular}

LDTg = Laterodorsal tegmental nucleus

LH = Luteinizing hormone

LHRH = Luteinizing hormone releasing hormone

LS

mAchR

MC

$\mathrm{MeA}$

mGluR

MLA

MPEP

MPZP

= Lateral septum

$=$ Muscarinic acetylcholine receptor

$=$ Melanocortins

$=$ Medial nucleus of amygdala

$=$ Metabotropic glutamate receptor

$=$ Methyllycaconitine

$=\quad 2-$ Methyl- 6 -(phenylethynyl $)$-pyridine

$=\quad(\mathrm{N}, \mathrm{N}-\mathrm{bis}(2-\mathrm{methoxyethyl})-3-(4-\mathrm{methoxy}-2-$ methylphenyl)-2,5-dimethylpyrazolo[ 1,5a]pyrimidin-7-amine)

MSH

$=$ Melanocyte stimulating hormone

MSH

MTEP

$=$ Melanocyte stimulating hormone

$=\quad 3-[(2-$ methyl-1,3-thiazol-4-yl)ethynyl $]-$ pyridine

\section{ACKNOWLEDGMENT}

Supported by an Exchange Award granted to Dr. Leggio from the European Foundation for Alcohol Research (ERAB).

\section{REFERENCES}

References 362-364 are related articles recently published.

[1] Spanagel R. Alcoholism: a systems approach from molecular physiology to addictive behaviour. Physiol Rev 2009; 89: 649-705.

[2] Boileau I, Assaad JM, Pihl RO, et al. Alcohol promotes dopamine release in the human nucleus accumbens. Synapse 2003; 49(4): 226-31.

[3] Diana M, Pistis M, Carboni S, et al. Profound decrement of mesolimbic dopaminergic neuronal activity during ethanol withdrawal syndrome in rats: electrophysiological and biochemical evidence. Proc Natl Acad Sci USA 1993; 90(17): 7966-9.

[4] Diana M, Pistis M, Muntoni A, et al. Mesolimbic dopaminergic reduction outlasts ethanol withdrawal syndrome: evidence of protracted abstinence. Neuroscience 1996; 71(2): 411-5.

[5] Weiss M, Schneider EM, Tarnow J, et al. Is inhibition of oxygen radical production of neutrophils by sympathomimetics mediated via beta-2 adrenoceptors? J Pharmacol Exp Ther 1996; 278(3): 110513.

MTIP = 3-(4-Chloro-2-morpholin-4-yl-thiazol-5-yl)-8(1-ethylpropyl)- 2,6-dimethyl-imidazo[1,2b]pyridazine

N/OFQ = Nociceptin/Orphanin FQ

$\mathrm{NAc}$

$=$ Nucleus accumbens

$\mathrm{nAchR} \quad=\quad$ Nicotinic acetylcholine receptor

NAM $=$ Negative allosteric modulator

[6] Martinez D, Kim JH, Krystal J, et al. Imaging the neurochemistry of alcohol and substance abuse. Neuroimaging Clin N Am 2007; 17(4): 539-55.

[7] Volkow ND, Wang GJ, Telang F, et al. Profound decreases in dopamine release in striatum in detoxified alcoholics: possible orbitofrontal involvement. J Neurosci 2007; 27(46): 12700-6.

[8] Vengeliene V, Bilbao A, Molander A, et al. Neuropharmacology of alcohol addiction. Br J Pharmacol 2008; 154(2): 299-315.

$\mathrm{NE}$

$=$ Norepinephrine

[9] Bouza C, Angeles M, Muñoz A, et al. Efficacy and safety of naltrexone and acamprosate in the treatment of alcohol dependence: a systematic review. Addiction 2004; 99(7): 811-28.

$\mathrm{NE} \quad=\quad$ Norepinephrine system

NK1R = Neurokinin 1 receptor

[10] Krampe H, Ehrenreich H. Supervised disulfiram as adjunct to psychotherapy in alcoholism treatment. Curr Pharm Des 2010; 19: 2076-90.

NK3R $=$ Tachykinin receptor 3

[11] Garbutt JC. Efficacy and tolerability of naltrexone in the management of alcohol dependence. Curr Pharm Des 2010; 19: 2091-7.

$\begin{array}{lll}\text { NOP } & =\quad \text { N-methyl-D-aspartic acid } \\ & =\quad \text { Nociceptin/orphanin peptide }\end{array}$

[12] Kiefer F, Mann K. Acamprosate: how, where, and for whom does it work? Mechanism of action, treatment targets, and individualized therapy. Curr Pharm Des 2010; 19: 2098-102.

$\mathrm{NP} 078585=1-(6,6-$ bis(4-fluorophenyl $)$ hexyl $)-4-(3,4,5-$ trimethoxybenzyl) piperazine

[13] Johnson BA, Ait-Daoud N. Topiramate in the new generation of drugs: efficacy in the treatment of alcoholic patients. Curr Pharm Des 2010; 19: 2103-12.

npEW $\quad=\quad$ Non-preganglionic Edinger-Westphal

[14] Kenna GA. Medications acting on the serotonergic system in the treatment of alcoholic patients. Curr Pharm Des 2010; 19: 2126-35.

NPY

ORL-1

$=$ Neuropeptide $\mathrm{Y}$ 
[15] Addolorato G, Leggio L. Safety and efficacy of baclofen in the treatment of alcohol-dependent patients. Curr Pharm Des 2010; 19: $2113-17$

[16] Swift RM. Medications acting on the dopaminergic system in the treatment of alcoholic patients. Curr Pharm Des 2010; 19: 2136-40.

[17] Fattore L, Fadda P, Fratta W. Endocannabinoid regulation of relapse mechanisms. Pharmacol Res 2007; 56(5): 418-27.

[18] Hungund BL, Basavarajappa BS. Role of endocannabinoids and cannabinoid CB1 receptors in alcohol-related behaviors. Ann N Y Acad Sci 2004; 1025: 515-27.

[19] Malinen H, Hyytiä P. Ethanol self-administration is regulated by CB1 receptors in the nucleus accumbens and ventral tegmental area in alcohol-preferring AA rats. Alcohol Clin Exp Res 2008; 32(11): 1976-83.

[20] Heilig M, Egli M. Pharmacological treatment of alcohol dependence: target symptoms and target mechanisms. Pharmacol Ther 2006; 111(3): 855-76.

[21] Basavarajappa BS, Cooper TB, Hungund BL. Chronic ethanol administration down-regulates cannabinoid receptors in mouse brain synaptic plasma membrane. Brain Res 1998; 793(1-2): 212-8.

[22] Basavarajappa BS, Hungund BL. Down-regulation of cannabinoid receptor agonist-stimulated [35S]GTP gamma S binding in synaptic plasma membrane from chronic ethanol exposed mouse. Brain Res1999; 815(1): 89-97.

[23] Basavarajappa BS. The endocannabinoid signaling system: a potential target for next-generation therapeutics for alcoholism. Mini Rev Med Chem 2007; 7(8): 769-79.

[24] Colombo G, Serra S, Brunetti G, et al. Stimulation of voluntary ethanol intake by cannabinoid receptor agonists in ethanol-preferring sP rats. Psychopharmacology (Berl) 2002; 159(2): 181-7.

[25] Hungund BL, Szakall I, Adam A, et al. Cannabinoid CB1 receptor knockout mice exhibit markedly reduced voluntary alcohol consumption and lack alcohol-induced dopamine release in the nucleus accumbens. J Neurochem 2003; 84(4): 698-704.

[26] Naassila M, Pierrefiche O, Ledent C, et al. Decreased alcohol selfadministration and increased alcohol sensitivity and withdrawal in CB1 receptor knockout mice. Neuropharmacology 2004; 46(2): 243-53.

[27] Poncelet M, Maruani J, Calassi R, et al. Overeating, alcohol and sucrose consumption decrease in CB1 receptor deleted mice. Neurosci Lett 2003; 343(3): 216-8.

[28] Thanos PK, Dimitrakakis ES, Rice O, et al. Ethanol selfadministration and ethanol conditioned place preference are reduced in mice lacking cannabinoid CB1 receptors. Behav Brain Res 2005; 164(2): 206-13.

[29] Malinen H, Hyytiä P. Ethanol self-administration is regulated by CB1 receptors in the nucleus accumbens and ventral tegmental area in alcohol-preferring AA rats. Alcohol Clin Exp Res 2008; 32(11): 1976-83.

[30] Rinaldi-Carmona M, Barth F, He'aulme M, et al. SR141716A, a potent and selective antagonist of the brain cannabinoid receptor. FEBS Lett 1994; 350: 240-4

[31] Serra S, Carai MA, Brunetti G, et al. The cannabinoid receptor antagonist SR 141716 prevents acquisition of drinking behavior in alcohol-preferring rats. Eur J Pharmacol 2001; 430(2-3): 369-71.

[32] Bell RL, Rodd ZA, Sable HJK, et al. Cannabinoid CB1 antagonist reduces alcohol intake during acquisition, maintenance, and relapse in inbred alcohol preferring (IP) rats. Abstract Viewer/Itinerary Planner. Washington DC: Society for Neuroscience 2004; Program No. 489.6

[33] Poncelet M, Maruani J, Calassi R, et al. Overeating, alcohol and sucrose consumption decrease in CB1 receptor deleted mice. Neurosci Lett 2003; 343(3): 216-8.

[34] Lallemand F, Soubrié PH, De Witte PH. Effects of CB1 cannabinoid receptor blockade on ethanol preference after chronic ethanol administration. Alcohol Clin Exp Res 2001; 25(9): 1317-23.

[35] Colombo G, Agabio R, Fà M, et al. Reduction of voluntary ethanol intake in ethanol-preferring $\mathrm{sP}$ rats by the cannabinoid antagonist SR-141716. Alcohol Alcohol 1998; 33(2): 126-30.

[36] Colombo $\mathrm{G}$, Orrù $\mathrm{A}$, Lai $\mathrm{P}$, et al. The cannabinoid $\mathrm{CB} 1$ receptor antagonist, rimonabant, as a promising pharmacotherapy for alcohol dependence: preclinical evidence. Mol Neurobiol 2007; 36(1): $102-12$.

[37] Dyr W, Ligieza J, Kostowski W. The effect of cannabinoid CB(1) receptor antagonist rimonabant (SR-141716) on ethanol drinking in high-preferring rats. Alcohol 2008; 42(6): 509-12.
[38] Lallemand F, Soubrié P, De Witte P. Effects of CB1 cannabinoid receptor blockade on ethanol preference after chronic alcohol administration combined with repeated re-exposures and withdrawals. Alcohol Alcohol 2004; 39(6): 486-92.

[39] Freedland CS, Sharpe AL, Samson HH, et al. Effects of SR141716A on ethanol and sucrose self-administration. Alcohol Clin Exp Res 2001; 25(2): 277-82.

[40] Hansson AC, Bermúdez-Silva FJ, Malinen H, et al. Genetic impairment of frontocortical endocannabinoid degradation and high alcohol preference. Neuropsychopharmacology 2007; 32(1): 11726.

[41] Rodd ZA, Bell RL, Pommer TJ, et al. The CB1 antagonist SR141716 transiently reduces operant ethanol selfadministration during relapse and maintenance, and inhibits alcohol seeking in alcohol-preferring (P) rats. Alcohol Clin Exp Res 2005; 29: 19A.

[42] Roberto M, Cruz M, Bajo M, et al. The Endocannabinoid System Tonically Regulates Inhibitory Transmission and Depresses the Effect of Ethanol in Central Amygdala. Neuropsychopharmacology 2010 May 12. [Epub ahead of print]

[43] Serra S, Brunetti G, Pani M, et al. Blockade by the cannabinoid $\mathrm{CB}$ (1) receptor antagonist, SR 141716, of alcohol deprivation effect in alcoholpreferring rats. Eur J Pharmacol 2002; 443: 95-7.

[44] Cippitelli A, Bilbao A, Hansson AC, et al. Cannabinoid CB1 receptor antagonism reduces conditioned reinstatement of ethanolseeking behaviour in rats. Eur J Neurosci 2005; 21: 2243-51.

[45] Parsons LH. Evidence for an endocannabinoid influence in the regulation of ethanol self-administration. Alcohol Clin Exp Res 2005; 29: 12

[46] Economidou D, Mattioli L, Cifani C, et al. Effect of the cannabinoid CB1 receptor antagonist SR-141716A on ethanol selfadministration and ethanol-seeking behaviour in rats. Psychopharmacology (Berl) 2006; 183: 394-403.

[47] Rinaldi-Carmona M, Barth F, Congy C, et al. SR147778 [5-(4bromophenyl)-1-(2,4-dichlorophenyl)-4-ethyl-N-(1-piperidinyl)-

1H-pyrazole-3-carboxamide], a new potent and selective antagonist of the CB1 cannabinoid receptor: biochemical and pharmacological characterization. J Pharmacol Exp Ther 2004; 310: 905-14.

[48] Gessa GL, Serra S, Vacca G, et al. Suppressing effect of the cannabinoid CB1 receptor antagonist, SR147778, on alcohol intake and motivational properties of alcohol in alcohol-preferring $\mathrm{sP}$ rats Alcohol Alcohol 2005; 40: 46-53.

[49] Soyka M, Koller G, Schmidt P, et al. Cannabinoid receptor 1 blocker rimonabant (SR 141716) for treatment of alcohol dependence: results from a placebo-controlled, double-blind trial. J Clin Psychopharmacol 2008; 28(3): 317-24.

[50] George DT, Herion DW, Jones CL, et al. Rimonabant (SR141716) has no effect on alcohol selfadministration or endocrine measures in nontreatment-seeking heavy alcohol drinkers. Psychopharmacology 2009, in press.

[51] Swift RM, Leggio L. Adjunctive Pharmacotherapy in the Treatment of Alcohol and Drug Dependence. In: Peter M, Ed. EvidenceBased Addiction Treatment. USA: Elsevier 2009; pp. 287-310.

[52] Abraham WC. Metaplasticity: tuning synapses and networks for plasticity. Nat Rev Neurosci 2008; 9: 387-99.

[53] Parsons CG, Danysz W, Zieglgänsberger W. Excitatory amino acid neurotransmission. Handb Exp Pharmacol 2005; (169): 249-303.

[54] Olive MF. Metabotropic glutamate receptor ligands as potential therapeutics for addiction. Curr Drug Abuse Rev 2009; 2(1): 83989.

[55] Gass JT, Olive MF. Transcriptional profiling of the rat frontal cortex following administration of the mGlu5 receptor antagonists MPEP and MTEP. Eur J Pharmacol 2008; 584(2-3): 253-62.

[56] Vosler PS, Bombace JC, Kosten TA. A discriminative two-lever test of dizocilpine's ability to reinstate ethanol-seeking behavior. Life Sci 2001; 69(5): 591-8

[57] Vosburg SK, Hart CL, Haney M, et al. An evaluation of the reinforcing effects of memantine in cocaine-dependent humans. Drug Alcohol Depend 2005; 79(2): 257-60.

[58] Bisaga A, Evans SM. Acute effects of memantine in combination with alcohol in moderate drinkers. Psychopharmacology 2004; 172: 16-24.

[59] Krupitsky EM, Neznanova O, Masalov D, et al. Effect of memantine on cue-induced alcohol craving in recovering alcoholdependent patients. Am J Psychiatry 2007; 164: 519-23. 
[60] Krupitsky EM, Rudenko AA, Burakov AM, et al. Antiglutamatergic strategies for ethanol detoxification: comparison with placebo and diazepam. Alcohol Clin Exp Res 2007; 31: 604-11.

[61] Evans SM, Levin FR, Brooks DJ, et al. A pilot double-blind treatment trial of memantine for alcohol dependence. Alcohol Clin Exp Res 2007; 31: 775-82

[62] Sanchis-Segura C, Borchardt T, Vengeliene V, et al. Involvement of the AMPA receptor GluR-C subunit in alcohol-seeking behaviour and relapse. J Neurosci 2006; 26: 1231-8.

[63] Krebs M, Leopold K, Richter C, et al. Levetiracetam for the treatment of alcohol withdrawal syndrome: an open-label pilot trial. J Clin Psychopharmacol 2006; 26: 347-9.

[64] Sarid-Segal O, Piechniczek-Buczek J, Knapp C, et al. The effects of levetiracetam on alcohol consumption in alcohol-dependent subjects: an open label study. Am J Drug Alcohol Abuse 2008; 34(4): 441-7.

[65] Dhami GK, Ferguson SS. Regulation of metabotropic glutamate receptor signaling, desensitization and endocytosis. Pharmacol Ther 2006; 111(1): 260-71.

[66] Pisani A, Calabresi P, Centonze D, et al. Enhancement of NMDA responses by group I metabotropic glutamate receptor activation in striatal neurones. Br J Pharmacol 1997; 120(6): 1007-14

[67] Spanagel R, Bienkowski P. Glutamatergic mechanisms in alcohol dependence and addiction. In: Lodge D, Danysz W, Parsons CG, Eds. Therapeutic Potential of Ionotropic Glutamate Receptor Antagonists and Modulators. Johnson City, TN, USA: Graham Publishing Co. 2002; pp. 375-403.

[68] Gasparini F, Lingenhöhl K, Stoehr N, et al. 2-Methyl-6(phenylethynyl)-pyridine (MPEP), a potent, selective and systemically active mGlu5 receptor antagonist. Neuropharmacology 1999; 38(10): 1493-503

[69] Carroll FI. Antagonists at metabotropic glutamate receptor subtype 5: structure activity relationships and therapeutic potential for addiction. Ann N Y Acad Sci 2008; 1141: 221-32.

[70] Bäckström P, Bachteler D, Koch S, et al. mGluR5 antagonist MPEP reduces ethanol-seeking and relapse behaviour. Neuropsychopharmacology 2004; 29(5): 921-8.

[71] Besheer J, Stevenson RA, Hodge CW. mGlu5 receptors are involved in the discriminative stimulus effects of self-administered ethanol in rats. Eur J Pharmacol 2006; 551: 71-5.

[72] Cosford ND, Tehrani L, Roppe J, et al. 3-[(2-Methyl-1,3-thiazol-4yl)ethynyl]-pyridine: a potent and highly selective metabotropic glutamate subtype 5 receptor antagonist with anxiolytic activity. J Med Chem 2003; 46(2): 204-6.

[73] Cowen MS, Adams C, Kraehenbuehl T, et al. The acute anticraving effect of acamprosate in alcohol-preferring rats is associated with modulation of the mesolimbic dopamine system. Addict Biol 2005; 10: 233-42

[74] Cowen MS, Krstew E, Lawrence AJ. Assessing appetitive and consummatory phases of ethanol self-administration in C57BL/6J mice under operant conditions: regulation by mGlu5 receptor antagonism. Psychopharmacology (Berl) 2007; 190(1): 21-9.

[75] Besheer J, Grondin JJ, Salling MC, et al. Interoceptive effects of alcohol require mGlu5 receptor activity in the nucleus accumbens. J Neurosci 2009; 29: 9582-91.

[76] Bäckström P, Hyytiä P. Suppression of alcohol self-administration and cue-induced reinstatement of alcohol seeking by the mGlu2/3 receptor agonist LY379268 and the mGlu8 receptor agonist (S)3,4-DCPG. Eur J Pharmacol 2005; 528(1-3): 110-8.

[77] Rodd ZA, McKinzie DL, Bell RL, et al. The metabotrobic glutamate 2/3 receptor agonist LY404039 reduces alcohol-seeking but not alcohol self-administration in alcohol-preferring $(\mathrm{P})$ rats. Brain Res 2006; 171: 207-15.

[78] Zhao Y, Dayas CV, Aujla H, et al. Activation of group II metabotropic glutamate receptors attenuates both stress and cueinduced ethanol-seeking and modulates c-fos expression in the hippocampus and amygdala. J Neurosci 2006; 26(39): 9967-74.

[79] Camron OG. Anxious-depressive comorbidity: effects on HPA axis and CNS noradrenergicfunction. Essent Psychopharmocol 2006; 7 : 24-34.

[80] Abelson JL, Liberzon I, Young EA, et al. Cognitive modulation of the endocrine stress response to a pharmacological challenge in normal and panic disorder subjects. Arch Gen Psychiatry 2005; 62: 668-75.

[81] Sinha R. How does stress increase risk of drug abuse and relapse? Psychophamacology 2001; 158: 343-59.
[82] Clarke TK, Schumann G. Gene-environment interactions resulting in risk alcohol drinking behaviour are mediated by CRF and CRF1. Pharmacol Biochem Behav 2009; 93(3): 230-6.

[83] Gray TS, Bingaman EW. The amygdala: corticotropin-releasing factor, steroids, and stress. Crit Rev Neurobiol 1996; 10(2): 155-68.

[84] Tsigos C, Chrousos GP. Physiology of the hypothalamic-pituitaryadrenal axis in health and dysregulation in psychiatric and autoimmune disorders. Endocrinol Metab Clin North Am 1994; 23: $451-$ 66.

[85] Merlo Pich E, Lorang M, Yeganeh M, et al. Increase of extracellular corticotropin-releasing factor-like immunoreactivity levels in the amygdala of awake rats during restraint stress and ethanol withdrawal as measured by microdialysis. J Neurosci 1995; 15(8): 5439-47.

[86] Olive MF, Koenig HN, Nannini MA, et al. Elevated extracellular CRF levels in the bed nucleus of the stria terminalis during ethano withdrawal and reduction by subsequent ethanol intake. Pharmacol Biochem Behav 2002; 72(1-2): 213-20.

[87] Baldwin HA, Rassnick S, Rivier J, et al. CRF antagonist reverses the "anxiogenic" response to ethanol withdrawal in the rat. Psychopharmacology (Berl) 1991; 103(2): 22732.

[88] Lovenberg TW, Liaw CW, Grigoriadis DE, et al. Cloning and characterization of a functionally distinct corticotropin-releasing factor receptor subtype from rat brain. Proc Natl Acad Sci USA 1995; 92(3): 836-40.

[89] Van Pett K, Viau V, Bittencourt JC, et al. Distribution of mRNAs encoding CRF receptors in brain and pituitary of rat and mouse. $\mathrm{J}$ Comp Neurol 2000; 428(2): 191-212.

[90] Stenzel-Poore MP, Cameron VA, Vaughan J, et al. Development of Cushing's syndrome in corticotropin-releasing factor transgenic mice. Endocrinology 1992; 130: 3378-86

[91] Smith GW, Aubry JM, Dellu F, et al. Corticotropin releasing factor receptor 1-deficient mice display decreased anxiety, impaired stres response, and aberrant neuroendocrine development. Neuron 1998; 20(6): 1093-102.

[92] Takahashi LK, Ho SP, Livanov V, et al. Antagonism of CRF(2) receptors produces anxiolytic behaviour in animal models of anxiety. Brain Res 2001; 902: 135-42.

[93] Bale TL, Contarino A, Smith GW, et al. Mice deficient for corticotropin-releasing hormone receptor-2 display anxiety-like behaviour and are hypersensitive to stress. Nat Genet 2000; 24(4): 410-4.

[94] Hansson AC, Cippitelli A, Sommer WH, et al. Variation at the rat Crhr1 locus and sensitivity to relapse into alcohol seeking induced by environmental stress. Proc Natl Acad Sci USA 2006; 103(41): 15236-41.

[95] Hansson AC, Cippitelli A, Sommer WH, et al. Region-specific down-regulation of Crhr1 gene expression in alcohol-preferring $\mathrm{msP}$ rats following ad lib access to alcohol. Addict Biol 2007; 12(1): 30-4.

[96] Sommer WH, Rimondini R, Hansson AC, et al. Upregulation of voluntary alcohol intake, behavioural sensitivity to stress, and amygdala crhrl expression following a history of dependence. Biol Psychiatry 2008; 63(2): 139-45.

[97] Treutlein J, Kissling C, Frank J, et al. Genetic association of the human corticotrophin releasing hormone receptor 1 (CRHR1) with binge drinking and alcohol intake patterns in two independent samples. Mol Psychiatry 2006; 11(6): 594-602.

[98] Blomeyer D, Treutlein J, Esser G, et al. Interaction between CRHR1 gene and stressful life events predicts adolescent heavy alcohol use. Biol Psychiatry 2008; 63(2): 146-51.

[99] Chu K, Koob GF, Cole M, et al. Dependence-induced increases in ethanol self-administration in mice are blocked by the CRF1 receptor antagonist antalarmin and by CRF1 receptor knockout. Pharmacol Biochem Behav 2007; 86(4): 813-21.

[100] Funk CK, Zorrilla EP, Lee MJ, et al. Corticotropin-Releasing Factor 1 Antagonists Selectively Reduce Ethanol Self-Administration in Ethanol-Dependent Rats. Biol Psychiatry 2007; 61(1): 78-86.

[101] Gilpin NW, Richardson HN, Koob GF. Effects of CRF1-receptor and opioid-receptor antagonists on dependence-induced increases in alcohol drinking by alcohol-preferring $(\mathrm{P})$ rats. Alcohol Clin Exp Res 2008; 32(9): 1535-42.

[102] Gehlert DR, Cippitelli A, Thorsell A, et al. 3-(4-Chloro-2 morpholin-4-yl-thiazol-5- yl)-8-(1-ethylpropyl)-2,6-dimethylimidazo[1,2-b]pyridazine: a novel brain penetrant, orally available corticotropin-releasing factor receptor 1 antagonist with efficacy in animal models of alcoholism. J Neurosci 2007; 27: 2718-26. 
[103] Sommer WH, Rimondini R, Hansson AC, et al. Upregulation of voluntary alcohol intake, behavioural sensitivity to stress, and amygdala crhr1 expression following a history of dependence. Biol Psychiatry 2008; 63(2): 139-45.

[104] Vaughan J, Donaldson C, Bittencourt J, et al. Urocortin, a mammalian neuropeptide related to fish urotensin I and to corticotropinreleasing factor. Nature $1995 ; 378(6554)$ : $287-92$

[105] Hsu SY, Hsueh AJ. Human stresscopin and stresscopin-related peptide are selective ligands for the type 2 corticotropin-releasing hormone receptor. Nat Med 2001; 7(5): 605-11.

[106] Reyes TM, Lewis K, Perrin MH, et al. Urocortin II: a member of the corticotropin-releasing factor (CRF) neuropeptide family that is selectively bound by type 2 CRF receptors. Proc Natl Acad Sci USA 2001; 98(5): 2843-8.

[107] Ryabinin AE, Tsivkovskaia NO, Ryabinin SA. Urocortin 1containing neurons in the human Edinger-Westphal nucleus. Neuroscience 2005; 134(4): 1317-23.

[108] Bittencourt JC, Vaughan J, Arias C, et al. Urocortin expression in rat brain: evidence against a pervasive relationship of urocortincontaining projections with targets bearing type 2 CRF receptors. J Comp Neurol 1999; 415(3): 285-312.

[109] Bachtell RK, Weitemier AZ, Ryabinin AE. Lesions of the EdingerWestphal nucleus in C57BL/6J mice disrupt ethanol-induced hypothermia and ethanol consumption. Eur J Neurosci 2004; 20: 161323.

[110] Chang SL, Patel NA, Romero AA. Activation and desensitization of Fos immunoreactivity in the rat brain following ethanol administration. Brain Res1995; 679: 89-98.

[111] Ryabinin AE, Criado JR, Henriksen SJ, et al. Differential sensitivity of c-Fos expression in hippocampus and other brain regions to moderate and low doses of alcohol. Mol Psychiatry 1997; 2: 32-43.

[112] Bachtell RK, Ryabinin AE. Interactive effects of nicotine and alcohol co-administration on expression of inducible transcription factors in mouse brain. Neuroscience 2001; 103: 941-54.

[113] Knapp DJ, Braun CJ, Duncan GE, et al. Regional specificity of ethanol and NMDA action in brain revealed with FOS-like immunohistochemistry and differential routes of drugadministration. Alcohol Clin Exp Res 2001; 25: 1662-72.

[114] Kolodziejska-Akiyama KM, Cha YM, Jiang Y, et al. Ethanolinduced FOS immunoreactivity in the brain of mu-opioid receptor knockout mice. Drug Alcohol Depend 2005; 80: 161-8.

[115] Topple AN, Hunt GE, McGregor IS. Possible neural substrates of beer-craving in rats. Neurosci. Lett. 1998; 252: 99-102.

[116] Bachtell RK, Wang YM, Freeman P, et al. Alcohol drinking produces brain region-selective changes in expression of inducible transcription factors. BrainRes 1999; 847: 157-65.

[117] Ryabinin AE, Bachtell RK, Freeman P, et al. ITF expression in mouse brain during acquisition of alcohol self-administration. Brain Res 2001; 890: 192-5.

[118] Weitemier AZ, Woerner A, Backstrom P, et al. Expression of c-Fos in Alko alcohol rats responding for ethanol in an operant paradigm. Alcohol Clin Exp Res 2001; 25: 704-10.

[119] Ryabinin AE, Galvan-Rosas A, Bachtell RK, et al. High alcohol/sucrose consumption during dark circadian phase in C57BL/6J mice: involvement of hippocampus, lateral septum and urocortinpositive cells of the Edinger-Westphal nucleus. Psychopharmacology (Berlin) 2003; 165: 296-305.

[120] Bachtell RK, Weitemier AZ, Galvan-Rosas A, et al. The EdingerWestphal-lateral septum urocortin pathway and its relationship to alcohol consumption. J. Neurosci 2003; 23: 2477-87.

[121] Sharpe AL, Tsivkovskaia NO, Ryabinin AE. Ataxia and c-Fos expression in mice drinking ethanol in a limited access session. Alcohol Clin Exp Res 2005; 29: 1419-26.

[122] Weitemier AZ, Ryabinin AE. Brain region-specific regulation of urocortin1 innervation and corticotropin-releasing factor receptor type 2 binding by ethanol exposure. Alcohol Clin Exp Res 2005; 29(9): 1610-20.

[123] Bachtell RK, Tsivkovskaia NO, Ryabinin AE. Strain differences in urocortin expression in the Edinger-Westphal nucleus and its relation to alcohol-induced hypothermia. Neuroscience 2002; 113(2): 421-34.

[124] Bachtell RK, Weitemier AZ, Galvan-Rosas A, et al. The EdingerWestphal-lateral septum urocortin pathway and its relationship to alcohol consumption. J Neurosci 2003; 23: 2477-87.
[125] Kiianmaa K, Hyytiä P, Samson HH, et al. New neuronal networks involved in ethanol reinforcement. Alcohol Clin Exp Res 2003; 27(2): 209-19.

[126] Bachtell RK, Weitemier AZ, Galvan-Rosas A, et al. The EdingerWestphal-lateral septum urocortin pathway and its relationship to alcohol consumption. J Neurosci 2003; 23: 2477-87.

[127] Weitemier AZ, Ryabinin AE. Lesions of the Edinger-Westhal nucleus alter food consumption. Behav Neurosci 2005; 119: 123543.

[128] Turek VF, Tsivkovskaia NO, Hyytia P, et al. Urocortin 1 expression in five pairs of rat lines selectively bred for differences in alcohol drinking. Psychopharmacology (Berlin) 2005; 181: 511-7.

[129] Bachtell RK, Weitemier AZ, Ryabinin AE. Lesions of the EdingerWestphal nucleus in C57BL/6J mice disrupt ethanol-induced hypothermia and ethanol consumption. Eur J Neurosci 2004; 20: 161323.

[130] Gonzales RA, Job MO, Doyon WM. The role of mesolimbic dopamine in the development and maintenance of ethanol reinforcement. Pharmacol Ther 2004; 103: 121-46.

[131] Liu J, Yu B, Neugebauer V, et al. Corticotropin-releasing factor and Urocortin I modulate excitatory glutamatergic synaptic transmission. J Neurosci 2004; 24: 4020-9.

[132] Liu J, Yu B, Orozco-Cabal L, et al. Chronic cocaine administration switches corticotropin-releasing factor2 receptor-mediated depression to facilitation of glutamatergic transmission in the lateral septum. J Neurosci 2005; 25: 577-83.

[133] Ryabinin AE, Weitemier AZ. The urocortin 1 neurocircuit: ethanolsensitivity and potential involvement in alcohol consumption. Brain Res Rev 2006; 52(2): 368-80.

[134] Ryabinin AE, Yoneyama N, Tanchuck MA, et al. Urocortin 1 microinjection into the mouse lateral septum regulates the acquisition and expression of alcohol consumption. Neuroscience 2008; 151(3): 780-90.

[135] Valdez GR, Sabino V, Koob GF. Increased anxiety-like behavior and ethanol self-administration in dependent rats: reversal via corticotropin-releasing factor-2 receptor activation. Alcohol Clin Exp Res 2004; 28(6): 865-72.

[136] Smith GW, Aubry JM, Dellu F, et al. Corticotropin releasing factor receptor 1-deficient mice display decreased anxiety, impaired stress response, and aberrant neuroendocrine development. Neuron 1998 20(6): 1093-102.

[137] Bale TL, Contarino A, Smith GW, et al. Mice deficient for corticotropin-releasing hormone receptor-2 display anxiety-like behaviour and are hypersensitive to stress. Nat Genet 2000; 24(4): 410-4.

[138] Bale TL, Picetti R, Contarino A, et al. Mice deficient for both corticotropin-releasing factor receptor 1 (CRFR1) and CRFR2 have an impaired stress response and display sexually dichotomous anxiety-like behaviour. J Neurosci 2002; 22(1): 193-9.

[139] Heilig M, McLeod S, Brot M, et al. Anxiolytic-like action of neuropeptide Y: mediation by Y1 receptors in amygdala, and dissociation from food intake effects. Neuropsychopharmacology 1993; 8(4): 357-63.

[140] Broqua P, Wettstein JG, Rocher MN, et al. Behavioral effects of neuropeptide $\mathrm{Y}$ receptor agonists in the elevated plus-maze and fear-potentiated startle procedures. Behav Pharmacol 1995; 6(3): 215-22.

[141] Britton KT, Southerland S, Van Uden E, et al. Anxiolytic activity of NPY receptor agonists in the conflict test. Psychopharmacology (Berl) 1997; 132(1): 6-13.

[142] Stogner KA, Holmes PV. Neuropeptide-Y exerts antidepressantlike effects in the forced swim test in rats. Eur J Pharmacol 2000; 387(2): R9-10.

[143] Redrobe JP, Dumont Y, Fournier A, et al. The neuropeptide Y (NPY) Y1 receptor subtype mediates NPY-induced antidepressantlike activity in the mouse forced swimming test. Neuropsychopharmacology 2002; 26(5): 615-24.

[144] Redrobe JP, Dumont Y, Quirion R. Neuropeptide Y (NPY) and depression: from animal studies to the human condition. Life Sci 2002; 71(25): 2921-37.

[145] Wahlestedt C, Yanaihara N, Hakanson R. Evidence for different pre- and post-junctional receptors for neuropeptide $\mathrm{Y}$ and related peptides. Regul Pept 1986; 13: 307-18.

[146] Thorsell A, Svensson P, Wiklund L, et al. Suppressed neuropeptide Y (NPY) mRNA in rat amygdala following restraint stress. Regul Pept 1998 ; 75-76: 247-54. 
[147] Thorsell A, Carlsson K, Ekman R, et al. Behavioral and endocrine adaptation, and up-regulation of NPY expression in rat amygdala following repeated restraint stress. Neuroreport 1999; 10(14): 3003-7.

[148] Thiele TE, Marsh DJ, Ste Marie L, et al. Ethanol consumption and resistance are inversely related to neuropeptide Y levels. Nature 1998; 396(6709): 366-9.

[149] Zhang H, Sakharkar AJ, Shi G, et al. Neuropeptide y signaling in the central nucleus of amygdala regulates alcohol-drinking and anxiety-like behaviors of alcohol-preferring rats. Alcohol Clin Exp Res 2010; 34(3): 451-61.

[150] Ehlers CL, Somes C, Cloutier D. Are some of the effects of ethanol mediated through NPY? Psychopharmacology (Berl) 1998; 139(12): 136-44.

[151] Hwang BH, Suzuki R, Lumeng L, et al. Innate differences in neuropeptide Y (NPY) mRNA expression in discrete brain regions between alcohol-preferring (P) and -nonpreferring (NP) rats: a significantly low level of NPY mRNA in dentate gyrus of the hippocampus and absence of NPY mRNA in the medial habenular nucleus of $\mathrm{P}$ rats. Neuropeptides 2004; 38(6): 359-68.

[152] Hwang BH, Zhang JK, Ehlers CL, et al. Innate differences of neuropeptide Y (NPY) in hypothalamic nuclei and central nucleus of the amygdale between selectively bred rats with high and low alcohol preference. Alcohol Clin Exp Res 1999; 23(6): 1023-30.

[153] Suzuki R, Lumeng L, McBride WJ, et al. Reduced neuropeptide Y mRNA expression in the central nucleus of amygdala of alcohol preferring $(\mathrm{P})$ rats: its potential involvement in alcohol preference and anxiety. Brain Res 2004; 1014(1-2): 251-4.

[154] Thorsell A, Repunte-Canonigo V, O'Dell LE, et al. Viral vectorinduced amygdala NPY overexpression reverses increased alcohol intake caused by repeated deprivations in Wistar rats. Brain 2007; 130(Pt 5): 1330-7.

[155] Cippitelli A, Damadzic R, Hansson AC, et al. Neuropeptide Y (NPY) suppresses yohimbine-induced reinstatement of alcohol seeking. Psychopharmacology (Berl) 2010; 208(3): 417-26.

[156] Thorsell A, Rimondini R, Heilig M. Blockade of central neuropeptide Y (NPY) Y2 receptors reduces ethanol self-administration in rats. Neurosci Lett 2002; 332(1): 1-4.

[157] Rimondini R, Thorsell A, Heilig M. Suppression of ethanol selfadministration by the neuropeptide Y (NPY) Y2 receptor antagonist BIIE0246: evidence for sensitization in rats with a history of dependence. Neurosci Lett 2005; 375(2): 129-33.

[158] Meunier JC, Mollereau C, Toll L, et al. Isolation and structure of the endogenous agonist of opioid receptor-like ORL1 receptor. Nature 1995; 377: 532-5.

[159] Mogil JS, Grisel JE, Reinscheid RK, et al. Orphanin FQ is a functional anti-opioid peptide. Neuroscience 1996; 75: 333-7.

[160] Mogil JS, Grisel JE, Zhangs G, et al. Functional antagonism of $\mu-$, $\delta$ - and $\kappa$-opioid antinociception by orphanin FQ. Neurosci Lett 1996; 214: 131-4.

[161] Ciccocioppo R, Angeletti S, Sanna PP, et al. Effect of nociceptin/orphanin FQ on the rewarding properties of morphine. Eur $\mathrm{J}$ Pharmacol 2000; 404: 153-9.

[162] Di Giannuario A, Pieretti S. Nociceptin differentially affects morphine-induced dopamine release from the nucleus accumbens and nucleus caudate in rats. Peptides 2000; 21: 1125-30.

[163] Martin-Fardon R, Zorrilla EP, Ciccocioppo R, et al. Role of innate anddrug-induced dysregulation of brain stress and arousal systems in addiction: Focus on corticotropin-releasing factor, nociceptin/orphanin FQ, and orexin/hypocretin. Brain Res 2010; 1314: 145-61.

[164] Xuei X, Flury-Wetherill L, Almasy L, et al. Association analysis of genes encoding the nociceptin receptor (OPRL1) and its endogenous ligand (PNOC) with alcohol or illicit drug dependence. Addict Biol 2008; 13: 80-7.

[165] Huang J, Young B, Pletcher MT, et al. Association between the nociceptin receptor gene (OPRL1) single nucleotide polymorphisms and alcohol dependence. Addict Biol 2008; 13(1): 88-94.

[166] Ciccocioppo R, Economidou D, Fedeli A, et al. Attenuation of ethanol self-administration and of conditioned reinstatement of alcohol-seeking behaviour by the antiopioid peptide nociceptin/orphanin FQ in alcohol-preferring rats. Psychopharmacology (Berl) 2004; 172(2): 170-8.

[167] Economidou D, Fedeli A, Fardon RM, et al. Effect of novel nociceptin/orphanin FQ-NOP receptor ligands on ethanol drinking in alcohol-preferring msP rats. Peptides 2006; 27(12): 3299-306.
[168] Kuzmin A, Kreek MJ, Bakalkin G, et al. The nociceptin/ orphanin FQ receptor agonist Ro 64-6198 reduces alcohol selfadministration and prevents relapse-like alcohol drinking. Neuropsychopharmacology 2007; 32: 902-10.

[169] Ciccocioppo R, Economidou D, Fedeli A, et al. The nociceptin/orphanin FQ/NOP receptor system as a target for treatment of alcohol abuse: a review of recent work in alcohol-preferring rats. Physiol Behav 2003; 79: 121-8.

[170] Martin-Fardon R, Ciccocioppo R, Massi M, et al. Nociceptin prevents stress-induced ethanol- but not cocaine-seeking behaviour in rats. Neuroreport 2000; 11: 1939-43.

[171] Ciccocioppo R, Economidou D, Fedeli A, et al. Attenuation of ethanol self-administration and of conditioned reinstatement of alcohol-seeking behaviour by the antiopioid peptide nociceptin/orphanin FQ in alcohol-preferring rats. Psychopharmacology (Berl.) 2004; 172: 170-8

[172] Economidou D, Fedeli A, Fardon RM, et al. Effect of novel nociceptin/orphanin FQNOP receptor ligands on ethanol drinking in alcohol-preferring msP rats. Peptides 2006; 27: 3299-306.

[173] Economidou D, Hansson AC, Weiss F, et al. Dysregulation of nociceptin/orphanin FQ activity in the amygdala is linked to excessive alcohol drinking in the rat. Biol Psychiatry 2008; 64: 211-8.

[174] Ciccocioppo R, Economidou D, Rimondini R, et al. Buprenorphine reduces alcohol drinking through activation of the nociceptin/orphanin FQ-NOP receptor system. Biol Psychiatry 2007; 61: 4-12.

[175] Kakko J, Svanborg KD, Kreek MJ, et al. 1-year retention and social function after buprenorphine-assisted relapse prevention treatment for heroin dependence in Sweden: a randomised,placebocontrolled trial. Lancet 2003; 361: 662-8.

[176] Euler US, Gaddum JH. An unidentified depressor substance in certain tissue extracts. J Physiol 1931; 72(1): 74-87.

[177] Fernandes ES, Schmidhuber SM, Brain SD. Sensory-nerve-derived neuropeptides: possible therapeutic targets. Handb Exp Pharmacol 2009; (194): 393-416.

[178] Heilig M, Thorsell A, Sommer WH, et al. Translating the neuroscience of alcoholism into clinical treatments: From blocking the buzz to curing the blues. Neurosci Biobehav Rev 2009 [Epub ahead of print].

[179] Kramer MS, Cutler N, Feighner J, et al. Distinct mechanism for antidepressant activity by blockade of central substance $\mathrm{P}$ receptors. Science 1998; 281(5383): 1640-5.

[180] Kramer MS, Winokur A, Kelsey J, et al. Demonstration of the efficacy and safety of a novel substance $\mathrm{P}$ (NK1) receptor antagonist in major depression. Neuropsychopharmacology 2004; 29(2): 385-92.

[181] Furmark T, Appel L, Michelgård A, et al. Cerebral blood flow changes after treatment of social phobia with the neurokinin-1 antagonist GR205171, citalopram, or placebo. Biol Psychiatry 2005; 58(2): 132-42.

[182] Holmes A, Heilig M, Rupniak NM, et al. Neuropeptide systems as novel therapeutic targets for depression and anxiety disorders. Trends Pharmacol Sci 2003; 24(11): 580-8.

[183] George DT, Gilman J, Hersh J, et al. Neurokinin 1 receptor antagonism as a possible therapy for alcoholism. Science 2008; 319(5869): 1536-9.

[184] Seneviratne C, Ait-Daoud N, Ma JZ, et al. Susceptibility locus in neurokinin-1 receptor gene associated with alcohol dependence. Neuropsychopharmacology 2009; 34(11): 2442-9.

[185] Ciccocioppo R, Panocka I, Polidori C, et al. Mechanism of action for reduction of ethanol intake in rats by the tachykinin NK-3 receptor agonist aminosenktide. Pharmacol Biochem Behav 1998; 61(4): 459-64.

[186] Massi M, Panocka I, deCaro G. The psychopharmacology of tachykinin NK-3 receptors in laboratory animals. Peptides 2000; 21: 1597-609.

[187] Ciccocioppo R, Panocka I, Pompei P, et al. Selective agonists at NK3 tachykinin receptors inhibit alcohol intake in Sardinian alcohol-preferring rats. Brain Res Bull 1994; 33: 71-7.

[188] Ciccocioppo R, Panocka I, Pompei P, et al. Subcutaneous injections of the tachykinin senktide reduce alcohol intake in alcoholpreferring rats. Peptides 1995; 16: 533-7.

[189] Panocka I, Ciccocioppo R, Polidori C, et al. Sensitivity of brain sites to the inhibitory effect on alcohol intake of the tachykinin aminosenktide. Peptides 1998; 19(5): 897-905. 
[190] Foroud T, Wetherill LF, Kramer J, et al. The tachykinin receptor 3 is associated with alcohol and cocaine dependence. Alcohol Clin Exp Res 2008; 32(6): 1023-30.

[191] Ahlstedt I, Engberg S, Smith J, et al. Occurrence and pharmacological characterization of four human tachykinin NK2 receptor variants. Biochem Pharmacol 2008; 76(4): 476-81.

[192] Louis C, Stemmelin J, Boulay D, et al. Additional evidence for anxiolytic- and antidepressant-like activities of saredutant (SR48968), an antagonist at the neurokinin-2 receptor in various rodent-models. Pharmacol Biochem Behav 2008; 89(1): 36-45.

[193] Ciccocioppo R, Panocka I, Pompei P, et al. Selective agonists at NK3 tachykinin receptors inhibit alcohol intake in Sardinian alcohol-preferring rats. Brain Res Bull 1994; 33(1): 71-7.

[194] Reinscheid RK. Phylogenetic appearance of neuropeptide S precursor proteins in tetrapods. Peptides 2007; 28(4): 830-7.

[195] Reinscheid RK, Xu YL. Neuropeptide $S$ as a novel arousal promoting peptide transmitter. FEBS J 2005; 272(22): 5689-93.

[196] Pape HC, Jüngling K, Seidenbecher T, et al. Neuropeptide S: a transmitter system in the brain regulating fear and anxiety. Neuropharmacology 2010; 58(1): 29-34.

[197] Ruggeri B, Braconi S, Cannella N, et al. Neuropeptide s receptor gene expression in alcohol withdrawal and protracted abstinence in postdependent rats. Alcohol Clin Exp Res 2010; 34(1): 90-7.

[198] Liu X, Weiss F. Additive effect of stress and drug cues on reinstatement of ethanol seeking: exacerbation by history of dependence and role of concurrent activation of corticotropin-releasing factor and opioid mechanisms. J Neurosci 2002; 22: 7856-61.

[199] Cannella N, Economidou D, Kallupi M, et al. Persistent increase of alcohol-seeking evoked by neuropeptide S: an effect mediated by the hypothalamic hypocretin system. Neuropsychopharmacology 2009; 34: 2125-34.

[200] Badia-Elder NE, Henderson AN, Bertholomey ML, et al. The effects of neuropeptide $\mathrm{S}$ on ethanol drinking and other related behaviours in alcohol-preferring and -nonpreferring rats. Alcohol Clin Exp Res 2008; 32: 1380-7.

[201] Jungling K, Seidenbecher T, Sosulina L, et al. Neuropeptide Smediated control of fear expression and extinction: role of intercalated GABAergic neurons in the amygdala. Neuron 59: 298-310.

[202] Xu YL, Reinscheid RK, Huitron-Resendiz S, et al. Neuropeptide S: a neuropeptide promoting arousal and anxiolytic-like effects. Neuron 2008; 43: 487-97.

[203] Mitsukawa K, Lu X, Bartfai T. Galanin, galanin receptors and drug targets. Cell Mol Life Sci 2008; 65: 1796-805.

[204] Belfer I, Hipp H, Bollettino A, et al. Alcoholism is associated with GALR3 but not two other galanin receptor genes. Genes Brain Behav 2007; 6(5): 473-81.

[205] Kojima M, Hosoda H, Date Y, et al. Ghrelin is a growth-hormonereleasing acylated peptide from stomach. Nature 1999, 402(6762): 656-60.

[206] Loose MD, Ronnekleiv OK, Kelly MJ. Neurons in the rat arcuate nucleus are hyperpolarized by GABAB and mu-opioid receptor agonists: evidence for convergence at a ligandgated potassium conductance. Neuroendocrinology 1991; 54(6): 537-44.

[207] Katayama M, Nogami H, Nishiyama J, et al. Developmentally and regionally regulated expression of growth hormone secretagogue receptor mRNA in rat brain and pituitary gland. Neuroendocrinology 2000; 72(6): 333-40.

[208] Zigman JM, Jones JE, Lee CE, et al. Expression of ghrelin receptor mRNA in the rat and the mouse brain. J Comp Neurol 2006; 494(3): 528-48.

[209] Jerlhag E, Egecioglu E, Dickson SL, et al. Ghrelin stimulates locomotor activity and accumbal dopamine-overflow via central cholinergic systems in mice: Implications for its involvement in brain reward. Addict Biol 2006; 11(1): 45-54.

[210] Jerlhag E, Egecioglu E, Dickson SL, et al. Ghrelin administration into tegmental areas stimulates locomotor activity and increases extracellular concentration of dopamine in the nucleus accumbens. Addict Biol 2007; 12(1): 6-16.

[211] Jerlhag E, Egecioglu E, Dickson SL, et al. Alpha-conotoxin MIIsensitive nicotinic acetylcholine receptors are involved in mediating the ghrelin-induced locomotor stimulation and dopamine overflow in nucleus accumbens. Eur Neuropsychopharmacol 2008; 18(7): 508-18.

[212] Jerlhag E. Systemic administration of ghrelin induces conditioned place preference and stimulates accumbal dopamine. Addict Biol 2008; 13(3-4): 358-63.
[213] Jerlhag E, Egecioglu E, Landgren S. et al. Requirement of central ghrelin signaling for alcohol reward. Proc Natl Acad Sci USA 2009; 106(27): 11318-23.

[214] Leggio L. Role of the ghrelin system in alcoholism: Acting on the growth hormone secretagogue receptor to treat alcohol-related diseases. Drug News Perspect 2010; 23(3): 157-66.

[215] Barroso-Chinea P, Cruz-Muros I, Aymerich MS, et al. Striatal expression of GDNF and differential vulnerability of midbrain dopaminergic cells. Eur J Neurosci 2005; 21: 1815-27.

[216] Carnicella S, Ron D. GDNF--a potential target to treat addiction. Pharmacol Ther 2009; 122(1): 9-18.

[217] Koob GF, Sanna PP, Bloom FE. Neuroscience of addiction. Neuron 1998; 21, 467-476.

[218] He DY, McGough NN, Ravindranathan A, et al. Glial cell linederived neurotrophic factor mediates the desirable actions of the anti-addiction drug ibogaine against alcohol consumption. J Neurosci 2005; 25: 619-28.

[219] Carnicella S, Kharazia V, Jeanblanc J, et al. GDNF is a fastacting potent inhibitor of alcohol consumption and relapse. Proc Natl Acad Sci USA 2008; 105: 8114-9.

[220] Carnicella S, Ron D. GDNF--a potential target to treat addiction. Pharmacol Ther 2009; 122(1): 9-18.

[221] Yang F, Feng L, Zheng F, et al. GDNF acutely modulates excitability and A-type $\mathrm{K}(+)$ channels in midbrain dopaminergic neurons. Nat Neurosci 2001; 4: 1071-8.

[222] Consales C, Volpicelli F, Greco D, et al. GDNF signaling in embryonic midbrain neurons in vitro. Brain Res 2007; 1159: 28-39.

[223] He DY, Ron D. Autoregulation of glial cell line-derived neurotrophic factor expression: implications for the long-lasting actions of the anti-addiction drug, Ibogaine. FASEB J 2006; 20: 2420-2.

[224] Belin D, Deroche-Gamonet V, Jaber M. Cocaine-induced sensitization is associated with altered dynamics of transcriptional responses of the dopamine transporter, tyrosine hydroxylase, and dopamine D2 receptors in C57Bl/6J mice. Psychopharmacology (Berl) 2007; 193: 567-78.

[225] Kastin AJ, Akerstrom V, Pan W. Glial cell line-derived neurotrophic factor does not enter normal mouse brain. Neurosci Lett 2003; 340: $239-41$.

[226] Maciulaitis R, Kontrimaviciute V, Bressolle FM, et al. Ibogaine, an anti-addictive drug: pharmacology and time to go further in development. A narrative review. Hum Exp Toxicol 2008; 27: 181-94.

[227] He DY, McGough NN, Ravindranathan A, et al. Glial cell linederived neurotrophic factor mediates the desirable actions of the anti-addiction drug ibogaine against alcohol consumption. J Neurosci $2005 ; 25$ : 619-28.

[228] Maisonneuve IM, Glick SD. Anti-addictive actions of an iboga alkaloid congener: a novel mechanism for a novel treatment. Pharmacol Biochem Behav 2003; 75, 607-18.

[229] Ohta K, Fujinami A, Kuno S, et al. Cabergoline stimulates synthesis and secretion of nerve growth factor, brainderived neurotrophic factor and glial cell line-derived neurotrophic factor by mouse astrocytes in primary culture. Pharmacology 2004; 71: 162-8.

[230] Carnicella S, Ahmadiantehrani S, He DY, et al. The FDA-approved drug cabergoline decreases alcohol drinking and seeking behaviours via glial cell line-derived neurotrophic factor. Biol Psychiatry 2009 in revision.

[231] Raskin NH. Alcoholism or acetaldehydism? N Engl J Med 1975; 292: 422-3.

[232] Amit Z, Smith BR. A multi-dimensional examination of the positive reinforcing properties of acetaldehyde. Alcohol 1985; 2: 36770.

[233] Brown ZW, Amit Z, Rockman GE. Intraventricular selfadministration of acetaldehyde, but not ethanol, in naive laboratory rats. Psychopharmacology 1979; 64: 271-6.

[234] Rodd-Henricks ZA, Melendez RI, Zaffaroni A, et al. The reinforcing effects of acetaldehyde in the posterior ventral tegmental area of alcohol-preferring rats. Pharmacol. Biochem Behav 2002; 72: 55-64.

[235] Smith BR, Amit Z, Splawinsky J. Conditioned place preference induced by intraventricular infusions of acetaldehyde. Alcohol 1984; 1: 193-5.

[236] Quertemont E, De Witte P. Conditioned stimulus preference after acetaldehyde but not ethanol injections. Pharmacol Biochem Behav 2001; 68: 449-54. 
[237] Quintanilla ME, Tampier L. Acetaldehyde-reinforcing effects: differences in low-alcohol-drinking (UChA) and high-alcoholdrinking(UChB) rats. Alcohol 2003; 31: 63-9.

[238] Myers WD, Ng KT, Marzuki S, et al. Alteration of alcohol drinking in the rat by peripherally self-administered acetaldehyde. Alcohol 1984; 1: 229-36.

[239] Myers WD, Ng KT, Singer G. Ethanol preference in rats with a prior history of acetaldehyde self-administration. Experientia 1984; 40: $1008-10$.

[240] Melis M, Enrico P, Peana AT, et al. Acetaldehyde mediates alcohol activation of the mesolimbic dopamine system. Eur J Neurosci 2007; 6, 2824-33.

[241] Diana M, Peana AT, Sirca D, et al. Crucial role of acetaldehyde in alcohol activation of the mesolimbic dopamine system. Ann NY Acad Sci 2008; 1139: 307-17.

[242] Melis M, Diana M, Enrico P, et al. Ethanol and acetaldehyde action on central dopamine systems: mechanisms, modulation, and relationship to stress. Alcohol 2009; 43(7): 531-9.

[243] Salaspuro V, Hietala J, Kaihovaara P, et al. Removal of acetaldehyde from saliva by a slow-release buccal tablet of L-cysteine. Int $\mathbf{J}$ Cancer 2002; 97(3): 361-4.

[244] Salaspuro VJ, Hietala JM, Marvola ML, et al. Eliminating carcinogenic acetaldehyde by cysteine from saliva during smoking. Cancer Epidemiol Biomarkers Prev 2006; 15(1): 146-9.

[245] Salaspuro M. Interrelationship between alcohol, smoking, acetaldehyde and cancer. Novartis Found Symp 2007; 285: 80-9; discussion 89-96, 198-9.

[246] Shackebaei D, King N, Shukla B, et al. Mechanisms underlying the cardioprotective effect of L-cysteine. Mol Cell Biochem 2005; 277(1-2): 27-31. PubMed PMID: 16132711.

[247] Sprince H, Parker CM, Smith GG, et al. Protection against acetaldehyde toxicity in the rat by L-cysteine, thiamin and L-2methylthiazolidine-4-carboxylic acid. Agents Actions 1974; 4(2): 125-30.

[248] Peana AT, Assaretti AR, Muggironi G, et al. Reduction of ethanolderived acetaldehyde induced motivational properties by Lcysteine. Alcohol Clin Exp Res 2009; 33(1): 43-8.

[249] Peana AT, Muggironi G, Calvisi G, et al. 1-Cysteine reduces oral ethanol self-administration and reinstatement of ethanol-drinking behaviour in rats. Pharmacol Biochem Behav 2010; 94(3): 431-7.

[250] Eriksson CJ. The role of acetaldehyde in the actions of alcohol (update 2000). Alcohol Clin Exp Res 2001; 25, S5: 15S-32.

[251] Quintanilla ME, Tampier L, Sapag A, et al. Polymorphisms in the mitochondrial aldehyde dehydrogenase gene (Aldh2) determine peak blood acetaldehyde levels and voluntary ethanol consumption in rats. Pharmacogenet Genomics 2005; 15: 427-31.

[252] Suh JJ, Pettinati HM, Kampman KM, et al. The status of disulfiram: a half of a century later [see comment]. J Clin Psychopharmacol 2006; 26: 290-302.

[253] Keung WM, Vallee BL. Kudzu root: an ancient Chinese source of modern antidipsotropic agents. Phytochemistry 1998; 47(4): 499506.

[254] Keung WM, Vallee BL. Daidzin: a potent, selective inhibitor of human mitochondrial aldehyde dehydrogenase. Proc Natl Acad Sci USA 1993; 90: 1247-351.

[255] Lin RC, Guthrie S, Xie CI, et al. Isoflavonoid compounds extracted from Pueraria lobata suppress alcohol preference in a pharmacogenetic rat model for alcoholism. Alcohol Clin Exp Res 1996; 20: 659-63.

[256] Heyman GM, Keung WM, Vallee BL. Daidzin decreases ethanol consumption in rats. Alcohol Clin Exp Res 1996; 20: 1083-7.

[257] Overstreet DH, Lee YW, Rezvani AH, et al. Suppression of alcohol intake after administration of the Chinese herbal medicine, NPI028, and its derivatives. Alcohol Clin Exp Res 1996; 20: 221-7.

[258] Overstreet DH, Lee DYW, Chen YT, et al. The Chinese herbal medicine NPI-028 suppresses alcohol intake in alcoholpreferring rats and monkeys without inducing taste aversion. Perfusion 1998; 11: 381-90.

[259] Benlhabib E, Baker JI, Keyler DE, et al. Kudzu root extract suppresses voluntary alcohol intake and alcohol withdrawal symptoms in $\mathrm{P}$ rats receiving free access to water and alcohol. $\mathrm{J}$ Med Food. 2004; 7(2): 168-79.

[260] Benlhabib E, Baker JI, Keyler DE, et al. Effects of purified puerarin on voluntary alcohol intake and alcohol withdrawal symptoms in $\mathrm{P}$ rats receiving free access to water and alcohol. $\mathrm{J}$ Med Food 2004; 7(2): 180-6.
[261] Arolfo MP, Overstreet DH, Yao L, et al. Suppression of heavy drinking and alcohol seeking by a selective ALDH-2 inhibitor. Alcohol Clin Exp Res 2009; 33(11): 1935-44.

[262] Xie CI, Lin RC, Antony V, et al. Daidzin, an antioxidant isoflavonoid, decreases blood alcohol levels and shortens sleep time induced by ethanol intoxication. Alcohol Clin Exp Res 1994; 18(6): 1443-7.

[263] Carai MA, Agabio R, Bombardelli E,et al. Potential use of medicinal plants in the treatment of alcoholism. Fitoterapia 2000; 71, S1: S38-42.

[264] Overstreet DH, Kralic JE, Morrow AL, et al. NPI-031G (puerarin) reduces anxiogenic effects of alcohol withdrawal or benzodiazepine inverse or 5-HT2C agonists. Pharmacol Biochem Behav 2003; 75(3): 619-25.

[265] Shebek J, Rindone JP. A pilot study exploring the effect of kudzu root on the drinking habits of patients with chronic alcoholism. J Altern Complement Med 2000; 6(1): 45-8.

[266] Lukas SE, Penetar D, Berko J, et al. An extract of the Chinese herbal root kudzu reduces alcohol drinking by heavy drinkers in a naturalistic setting. Alcohol Clin Exp Res 2005; 29(5): 756-62.

[267] Crunelle CL, Miller ML, Booij J, et al. The nicotinic acetylcholine receptor partial agonist varenicline and the treatment of drug dependence: a review. Eur Neuropsychopharmacol 2010; 20(2): 6979

[268] Clarke PB, Fu DS, Jakubovic A, et al. Evidence that mesolimbic dopaminergic activation underlies the locomotor stimulant action of nicotine in rats. J Pharmacol Exp Ther 1998; 246: 701-8.

[269] Vengeliene V, Bilbao A, Molander A, et al. Neuropharmacology of alcohol addiction. Br J Pharmacol 2008; 154(2): 299-315.

[270] Blomqvist O, Ericson M, Johnson DH, et al. Voluntary ethanol intake in the rat: effects of nicotinic acetylcholine receptor blockade or subchronic nicotine treatment. Eur J Pharmacol 1996; 314(3): 257-67.

[271] Blomqvist O, Ericson M, Engel JA, et al. Accumbal dopamine overflow after ethanol: localization of the antagonizing effect of mecamylamine. Eur J Pharmacol 1997; 334 (2-3): 149-56.

[272] Blomqvist O, Engel JA, Nissbrandt H, et al. The mesolimbic dopamine-activating properties of ethanol are antagonized by mecamylamine. Eur J Pharmacol 1993; 249(2): 207-13.

[273] Ericson M, Blomqvist O, Engel JA, et al. Voluntary ethanol intake in the rat and the associated accumbal dopamine overflow are blocked by ventral tegmental mecamylamine. Eur J Pharmacol 1998; 358(3): 189-96.

[274] Farook JM, Lewis B, Gaddis JG, et al. Effects of mecamylamine on alcohol consumption and preference in male C57BL/6J mice. Pharmacology 2009; 83(6): 379-84.

[275] Kuzmin A, Jerlhag E, Liljequist S, et al. Effects of subunit selective $\mathrm{nACh}$ receptors on operant ethanol self-administration and relapse-like ethanol-drinking behaviour. Psychopharmacology (Berl) 2009; 203(1): 99-108.

[276] Bell RL, Eiler BJ, Cook JB, et al. Nicotinic receptor ligands reduce ethanol intake by high alcohol-drinking HAD-2 rats. Alcohol 2009; 43(8): 581-92.

[277] Jiménez-Ruiz C, Berlin I, Hering T. Varenicline: a novel pharmacotherapy for smoking cessation.Drugs 2009; 69(10): 1319-38.

[278] Kamens HM, Andersen J, Picciotto MR. Modulation of ethanol consumption by genetic and pharmacological manipulation of nicotinic acetylcholine receptors in mice. Psychopharmacology (Berl) 2010. [Epub ahead of print]

[279] Steensland P, Simms JA, Holgate J, et al. Varenicline, an alpha4beta2 nicotinic acetylcholine receptor partial agonist, selec tively decreases ethanol consumption and seeking. Proc Natl Acad Sci USA 2007; 104(30): 12518-23.

[280] Gulick D, Gould TJ. Varenicline ameliorates ethanol-induced deficits in learning in C57BL/6 mice. Neurobiol Learn Mem 2008 90(1): 230-6.

[281] Blomqvist O, Hernandez-Avila CA, Van Kirk J, et al. Mecamylamine modifies the pharmacokinetics and reinforcing effects of alcohol. Alcohol Clin Exp Res 2002; 26(3): 326-31.

[282] Chi H, de Wit H. Mecamylamine attenuates the subjective stimulant-like effects of alcohol in social drinkers. Alcohol Clin Exp Res 2003; 27(5): 780-6.

[283] Young EM, Mahler S, Chi H, et al. Mecamylamine and ethanol preference in healthy volunteers. Alcohol Clin Exp Res. 2005 29(1): 58-65. 
[284] McKee SA, Harrison EL, O'Malley SS, et al. Varenicline reduces alcohol self-administration in heavy drinking smokers. Biol Psychiatry 2009; 66(2): 185-90.

[285] Zhou C, Fryer AD, Jacoby DB. Structure of the human M(2) muscarinic acetylcholine receptor gene and its promoter. Gene 2001; 271: 87-92.

[286] Dick DM, Agrawal A, Wang JC, et al. Alcohol dependence with comorbid drug dependence: genetic and phenotypic associations suggest a more severe form of the disorder with stronger genetic contribution to risk. Addiction 2007; 102(7): 1131-9.

[287] Luo X, Kranzler HR, Zuo L, et al. CHRM2 gene predisposes to alcohol dependence, drug dependence and affective disorders: results from an extended case-control structured association study. Hum Mol Genet 2005; 14(16): 2421-34

[288] Söderpalm B, Ericson M, Olausson P, et al. Nicotinic mechanisms involved in the dopamine activating and reinforcing properties of ethanol. Behav Brain Res 2000; 113(1-2): 85-96.

[289] Samochocki M, Höffle A, Fehrenbacher A, et al. Galantamine is an allosterically potentiating ligand of neuronal nicotinic but not of muscarinic acetylcholine receptors. J Pharmacol Exp Ther 2003; 305(3): 1024-36.

[290] Opitz K. Verwendung von galanthamin zur behandlung des alkoholismus, Patent DE 4010079, 1992

[291] Iliev A, Traykov V, Prodanov D, et al. N. Effect of the acetylcholinesterase inhibitor galanthamine on learning and memory in prolonged alcohol intake rat model of acetylcholine deficit. Methods Find Exp Clin Pharmacol 1999; 21(4): 297-301.

[292] Doetkotte R, Opitz K, Kiianmaa K, et al. Reduction of voluntary ethanol consumption in alcohol-preferring Alko alcohol (AA) rats by desoxypeganine and galanthamine. Eur J Pharmacol 2005; 522(1-3): 72-7.

[293] Mann K, Ackermann K, Diehl A, et al. Galantamine: a cholinergic patch in the treatment of alcoholism: a randomized, placebocontrolled trial. Psychopharmacology (Berl) 2006; 184(1): 115-21.

[294] Gann H, Feige B, Hohagen F, et al. Sleep and the cholinergic rapid eye movement sleep induction test in patients with primary alcohol dependence. Biol Psychiatry 2001; 50(5): 383-90.

[295] Di Chiara G, Imperato A. Ethanol preferentially stimulates dopamine release in the nucleus accumbens of freely moving rats. Eur J Pharmacol 1985; 115(1): 131-2.

[296] Koob GF, Bloom FE. Cellular and molecular mechanisms of drug dependence. Science 1988; 242(4879): 715-23.

[297] Schofield P. Glycine: the other inhibitory neurotransmitter. Alcohol Clin Exp Res 1996; 20(S8): 219A-23.

[298] Zheng F, Johnson SW. Glycine receptor-mediated inhibition of dopamine and non-dopamine neurons of the rat ventral tegmental area in vitro. Brain Res 2001; 919(2): 313-7.

[299] Aguayo LG, Tapia JC, Pancetti FC. Potentiation of the glycineactivated $\mathrm{Cl}$ - current by ethanol in cultured mouse spinal neurons. $\mathrm{J}$ Pharmacol Exp Ther 1996; 279(3): 1116-22.

[300] Mascia MP, Machu TK, Harris RA. Enhancement of homomeric glycine receptor function by long-chain alcohols and anaesthetics. Br J Pharmacol 1996; 119(7): 1331-6.

[301] Molander A, Söderpalm B. Glycine receptors regulate dopamine release in the rat nucleus accumbens. Alcohol Clin Exp Res 2005; 29(1): 17-26.

[302] Molander A, Söderpalm B. Accumbal strychnine-sensitive glycine receptors: an access point for ethanol to the brain reward system. Alcohol Clin Exp Res 2005; 29(1): 27-37

[303] Molander A, Löf E, Stomberg R, et al. Involvement of accumbal glycine receptors in the regulation of voluntary ethanol intake in the rat. Alcohol Clin Exp Res 2005; 29(1): 38-45.

[304] Molander A, Lidö HH, Löf E, et al. The glycine reuptake inhibitor Org 25935 decreases ethanol intake and preference in male wistar rats. Alcohol Alcohol 2007; 42(1): 11-8.

[305] Ge J, Hamilton M, Shahid D, et al. The effects of Org 25935 on the extracellular levels of glycine in brain regions of freely moving rats using microdialysis. Br J Pharmacology 2001; 133: 135.

[306] Lidö HH, Stomberg R, Fagerberg A, et al. The glycine reuptake inhibitor org 25935 interacts with Basal and ethanol-induced dopamine release in rat nucleus accumbens. Alcohol Clin Exp Res 2009; 33(7): 1151-7.

[307] Tully K, Li Y, Tsvetkov E, et al. Norepinephrine enables the induction of associative long-term potentiation at thalamo-amygdala synapses. PNAS 2007; 104(35): 14146-50.
[308] Davis WM, Smith SG, Werner TE. Noradrenergic role in the selfadministration of ethanol. Pharmacol Biochem Behav 1978; 9: 36974

[309] Walker BM, Rasmussen DD, Raskind MA, et al. alpha1noradrenergic receptor antagonism blocks dependence-induced increases in responding for ethanol. Alcohol 2008; 42(2): 91-7.

[310] Mason BJ, Kocsis JH. Desipramine treatment of alcoholism. Psychopharmacol Bull 1991; 27: 155-61.

[311] Mason BJ, Kocsis JH, Ritvo EC, et al. A double-blind, placebocontrolled trial of desipramine for primary alcohol dependence stratified on the presence or absence of major depression. JAMA 1996; 275: 761-7.

[312] Reid LD, Delconte JD, Amendola CA, et al. alpha(2)-Adrenoceptor antagonists and propensity to take alcoholic beverages. Behav Pharmacol 1994; 5(4 - 5): 485-93.

[313] Marinelli PW, Funk D, Juzytsch W, et al. The CRF1 receptor antagonist antalarmin attenuates yohimbine-induced increases in operant alcohol self-administration and reinstatement of alcohol seeking in rats. Psychopharmacology (Berl) 2007; 195(3): 345-55.

[314] Rasmussen DD, Alexander LL, Raskind MA, et al. The alpha1adrenergic receptor antagonist, prazosin, reduces alcohol drinking in alcohol-preferring (P) rats. Alcohol Clin Exp Res 2009; 33(2): 264-72.

[315] Simpson TL, Saxon AJ, Meredith CW, et al. A pilot trial of the alpha-1 adrenergic antagonist, prazosin, for alcohol dependence. Alcohol Clin Exp Res 2009; 33(2): 255-63.

[316] Brodie MS, Scholz A, Weiger TM, et al. Ethanol interactions with calcium-dependent potassium channels. Alcohol Clin Exp Res 2007; 31(10): 1625-32.

[317] Treistman SN, Martin GE. BK Channels: mediators and models for alcohol tolerance. Trends Neurosci 2009; 32(12): 629-37.

[318] Brodie MS, McElvain MA, Bunney EB, et al. Pharmacological reduction of small conductance calcium-activated potassium current (SK) potentiates the excitatory effect of ethanol on ventral tegmental area dopamine neurons. J Pharmacol Exp Ther 1999; 290: 325-33.

[319] Brodie MS, Pesold C, Appel SB. Ethanol directly excites dopaminergic ventral tegmental area reward neurons. Alcohol Clin Exper Res 1999; 23: 1848-52

[320] Hopf FW, Martin M, Chen BT, et al. Withdrawal from intermittent ethanol exposure increases probability of burst firing in VTA neurons in vitro. J Neurophysiol 2007; 98: 2297-310.

[321] Brodie MS. Concurrent blockade of SK and h-current increases ethanol-induced excitation of dopaminergic ventral tegmental area neurons. Soc Neurosci Online 2005; Program No. 560.3.

[322] Hopf FW, Bowers MS, Chang SJ, et al. Reduced nucleus accumbens SK channel activity enhances alcohol seeking during abstinence. Neuron 2010; 65: 682-94.

[323] Ghezzi A, Al-Hasan YM, Larios LE, et al. slo K(+) channel gene regulation mediates rapid drug tolerance. Proc Natl Acad Sci USA 2004; 101(49): 17276-81.

[324] Martin G, Puig S, Pietrzykowski A, et al. Somatic localization of a specific large-conductance calcium-activated potassium channel subtype controls compartmentalized ethanol sensitivity in the nucleus accumbens. J Neurosci 2004; 24(29): 6563-72.

[325] Martin GE, Hendrickson LM, Penta KL, et al. Identification of a BK channel auxiliary protein controlling molecular and behavioral tolerance to alcohol. Proc Natl Acad Sci USA 2008; 105(45): 17543-8.

[326] Dolganiuc A, Bakis G, Kodys K, et al. Acute ethanol treatment modulates Toll-like receptor-4 association with lipid rafts. Alcohol Clin Exp Res 2006; 30(1): 76-85.

[327] Ellingson JS, Taraschi TF, Wu A, et al. Cardiolipin from ethanolfed rats confers tolerance to ethanol in liver mitochondrial membranes. Proc Natl Acad Sci USA 1988; 85(10): 3353-7.

[328] Dunlap K, Luebke JI, Turner TJ. Exocytotic Ca2channels in mammalian central neurons. Trends Neurosci 1995; 18: 89-98.

[329] Snutch TP. Targeting chronic and neuropathic pain: the N-type calcium channel comes of age. NeuroRx 2005; 2: 662-70.

[330] Huguenard JR. Low-threshold calcium currents in central nervous system neurons. Annu Rev Physiol 1996; 58: 329-48.

[331] Mu J, Carden WB, Kurukulasuriya NC, et al. Ethanol influences on native T-type calcium current in thalamic sleep circuitry. J Pharmacol Exp Ther 2003; 307: 197-204.

[332] Reid CA, Bekkers JM, Clements JD. Presynaptic Ca2+ channels: a functional patchwork. Trends Neurosci 2003; 26(12): 683-7. 
[333] Newton PM, Orr CJ, Wallace MJ, et al. Deletion of N-type calcium channels alters ethanol reward and reduces ethanol consumption in mice. J Neurosci 2004; 24(44): 9862-9.

[334] Newton PM, Zeng L, Wang V, et al. A blocker of N- and T-type voltage-gated calcium channels attenuates ethanol-induced intoxication, place preference, self-administration, and reinstatement. J Neurosci 2008; 28(45): 11712-9.

[335] Martin WR, Eades CG, Thompson JA, et al. The effects of morphine- and nalorphine-like drugs in the nondependent and morphine-dependent chronic spinal dog. J Pharmacol Exp Ther 1976; 197: 517-32.

[336] Miyatake R, Furukawa A, Matsushita S, et al. Functional polymorphisms in the sigmal receptor gene associated with alcoholism. Biol Psychiatry 2004; 55(1): 85-90.

[337] Sabino V, Cottone P, Zhao Y, et al. The sigma-receptor antagonist BD-1063 decreases ethanol intake and reinforcement in animal models of excessive drinking. Neuropsychopharmacology 2009; 34(6): 1482-93.

[338] Hadley ME, Haskell-Luevano C. The proopiomelanocortin system. Ann N Y Acad Sci 1999; 885: 1-21.

[339] Kokare DM, Singru PS, Dandekar MP, et al. Involvement of alphamelanocyte stimulating hormone (alpha-MSH) in differential ethanol exposure and withdrawal related depression in rat: neuroanatomical-behavioural correlates. Brain Res 2008; 1216: 53-67.

[340] Ploj K, Roman E, Kask A, et al. I. Effects of melanocortin receptor ligands on ethanol intake and opioid peptide levels in alcoholpreferring AA rats. Brain Res Bull 2002; 59(2): 97-104.

[341] Navarro M, Cubero I, Knapp DJ, et al. MTII-induced reduction of voluntary ethanol drinking is blocked by pre-treatment with AgRP(83-132). Neuropeptides 2003; 37(6): 338-44.

[342] Navarro M, Cubero I, Chen AS, et al. Effects of melanocortin receptor activation and blockade on ethanol intake: a possible role for the melanocortin-4 receptor. Alcohol Clin Exp Res 2005; 29: 949-57.

[343] Ebner K, Wotjak CT, Landgraf R, et al. Forced swimming triggers vasopressin release within the amygdala to modulate stress-coping strategies in rats. Eur J Neurosci 2002; 15(2): 384-8.

[344] Wigger A, Sánchez MM, Mathys KC, et al. Alterations in central neuropeptide expression, release, and receptor binding in rats bred for high anxiety: critical role of vasopressin. Neuropsychopharmacology 2004; 29(1): 1-14.

[345] Veinante P, Freund-Mercier MJ. Distribution of oxytocin- and vasopressin-binding sites in the rat extended amygdala: a histoautoradiographic study. J Comp Neurol 1997; 383(3): 305-25.

[346] Gulya K, Dave JR, Hoffman PL. Chronic ethanol ingestion decreases vasopressin mRNA in hypothalamic and extrahypothalamic nuclei of mouse brain. Brain Res 1991; 557: 129-35.

[347] Koob GF. A role for brain stress systems in addiction. Neuron 2008; 59(1): 11-34.

[348] Umathe SN, Bhutada PS, Dixit PV, et al. Leuprolide: a luteinizing hormone releasing hormone agonist attenuates ethanol withdrawal syndrome and ethanol-induced locomotor sensitization in mice. Neuropeptides 2008; 42(3): 345-53.
[349] Uday G, Pravinkumar B, Manish W, et al. LHRH antagonist attenuates the effect of fluoxetine on marble-burying behavior in mice. Eur J Pharmacol 2007; 563(1-3): 155-9.

[350] Belelli D, Lambert JJ. Neurosteroids: endogenous regulators of the GABA(A)receptor. Nat Rev Neurosci 2005; 6(7): 565-75.

[351] Patchev VK, Hassan AH, Holsboer DF, et al. The neurosteroid tetrahydroprogesterone attenuates the endocrine response to stress and exerts glucocorticoid-like effects on vasopressin gene transcription in the rat hypothalamus. Neuropsychopharmacology 1996; 15: 533-40.

[352] Finn DA, Sinnott RS, Ford MM, Long SL, et al. Sex differences in the effect of ethanol injection and consumption on brain allopregnanolone levels in C57BL/6 mice. Neuroscience 2004; 123: 813-9

[353] Torres JM, Ortega E. Alcohol intoxication increases allopregnanolone levels in male adolescent humans. Psychopharmacology 2004; 172: 352-5.

[354] Ford MM, Nickel JD, Phillips TJ, et al. Neurosteroid modulators of GABAA receptors differentially modulate ethanol intake patterns in male C57BL/6J mice. Alcohol Clin Exp Res 2005; 29: 1630-40.

[355] Ford MM, Nickel JD, Finn DA. Treatment with and withdrawal from finasteride alter ethanol intake patterns in male C57BL / 6J mice: potential role of endogenous neurosteroids? Alcohol 2005; 37: 23-33.

[356] Pierucci-Lagha A, Covault J, Feinn R, et al. GABRA2 alleles moderate the subjective effects of alcohol, which are attenuated by finasteride. Neuropsychopharmacology 2005; 30: 1193-203.

[357] Ford MM, Yoneyama N, Strong MN, et al. Inhibition of 5alphareduced steroid biosynthesis impedes acquisition of ethanol drinking in male C57BL/6J mice. Alcohol Clin Exp Res 2008; 32(8): 1408-16.

[358] Melis M, Spiga S, Diana M. The dopamine hypothesis of drug addiction: hypodopaminergic state. Int Rev Neurobiol 2005; 63: 101-54.

[359] Feil J, Zangen A. Brain stimulation in the study and treatment of addiction. Neurosci Biobehav Rev 2010; 34(4): 559-74.

[360] Roth Y, Amir A, Levkovitz Y, et al. Three-dimensional distribution of the electric field induced in the brain by transcranial magnetic stimulation using figure- 8 and deep H-coils. J Clin Neurophysiol 2007; 24(1): 31-8.

[361] Leggio L, Kenna GA, Fenton M, et al. Typologies of alcohol dependence. From Jellinek to genetics and beyond. Neuropsychol Rev 2009; 19(1): 115-29.

[362] Danysz W, Parsons CG, Jirgensons A, et al. Amino-alkylcyclohexanes as a novel class of uncompetitive NMDA receptor antagonists. Curr Pharm Des 2002; 8(10): 835-43.

[363] Raaijmakers JA, Koster ES, Maitland-van der Zee AH. Pharmacogenetics and the pharmaceutical industry. Curr Pharm Des 2010; 16(2): 238-44.

[364] Wang LL, Yang AK, He SM, et al. Identification of Molecular Targets Associated With Ethanol Toxicity and Implications in Drug Development. Curr Pharm Des 2010; 16(11): 1313-55. 